\title{
Estudio de un episodio de lluvia torrencial en Navarra con efectos de inundación
}

\author{
Javier María Pejenaute GoN̄ ${ }^{*}$
}

\section{RESUMEN}

Los primeros días de octubre de 1992 se caracterizaron por las abundantes precipitaciones que se registraron en los Valles Cantábricos y Pirenaicos de Navarra y que dieron lugar a fuertes crecidas de los ríos y a las inundaciones que afectaron a la mitad Norte de la Comunidad. El objetivo del presente trabajo es el estudio de las inundaciones de octubre de 1992 en Navarra, analizando las causas, repercusiones, intensidad, áreas afectadas y zonas de mayor riesgo. Los resultados, tanto de la dinámica atmosférica como de la cantidad caída y nivel de agua de los ríos, se compara con las últimas inundaciones de diciembre de 1992 y 1993.

Palabras clave: Climatología regional, precipitaciones torrenciales, inundaciones, otoño, comarcas navarras.

\section{ABSTRACT}

The first days of october of 1992 were characterized by the heavy rainfall that was reported in the Cantabrian and Pyrenean valleys of Navarra and that gave rise to rivers running in spate and the floods that had an effect on the north in this Community. This piece of work aims to study the floods in Navarra in october of 1992, analysing the reasons, repercussions, intensity, the affected areas and zones with a bigger risk. The results of the atmospheric dynamic as much as the rainfall and the water level of the rivers are compared to the last floods in december of 1992 and 1993.

\footnotetext{
* Profesor/tutor del Centro Asociado de la UNED de Navarra.
} 
Key words: Regional climatology, torrential rainfall, floods, autumn, Navarran areas.

\section{INTRODUCCIÓN}

Los episodios de lluvias intensas que dan lugar a peligrosas crecidas en el caudal de los ríos con inundaciones en sus cuencas, son los eventos que han causado mayores pérdidas humanas y materiales en los últimos años (OLCINA CANTOS, J., 1994). Cada vez más preocupan las riadas a los ciudadanos por las repercusiones que tienen en la economía. Es cierto que las inundaciones son difíciles de dominar, pues se deben a precipitaciones excesivamente altas en corto espacio de tiempo. En estos casos, el papel de los ciudadanos y de las políticas regionales será intentar reducir sus efectos. Si después de una riada se reconstruye lo destruido tal como estaba sin tener en cuenta las causas que han motivado el desastre, el problema no se resuelve. A veces será necesario adoptar medidas globales para solucionar el problema e incluso hacer una planificación adecuada de toda la cuenca de un río (Comunidad Autónoma del País Vasco, 1989).

Resulta claro que algunas actuaciones humanas aumentan el riesgo de inundaciones. La eliminación del bosque autóctono y su sustitución por parcelas de cultivo o por masas forestales de rápido desarrollo, disminuye el papel protector que tenia. Esto hace que la acumulación en los cauces de agua sea superior y que aumente la carga sólida de piedras y arenas que llevan las aguas en suspensión hacia las partes bajas. Por otra parte, las redes de alcantarillado en las ciudades están diseñadas para evacuar cantidades normales de agua, pero cuando las lluvias son abundantes se llenan por completo e incapaces de absorber grandes cantidades de agua, se convierten en auténticas fuentes por las que mana el agua.

Los daños ocasionados no suelen tener lugar en las zonas montañosas o ćabecera de los valles donde nacen los ríos, donde más llueve y hay menos población, sino en las partes bajas o llanuras, en nuestro caso en la Cuenca de Pamplona, Navarra Media y la Ribera; es decir, donde se asientan los pueblos y las ciudades. Si la riada es fuerte se interrumpen las comunicaciones y el suministro de luz y agua potable. $Y$ una vez pasada la crecida, los esfuerzos se centran en reconstruir los desperfectos y olvidar los malos momentos, hasta que otra nueva haga su aparición. Así, las vías de comunicación se reconstruyen, los cauces se limpian de vege- 
tación, se quitan las piedras y la tierra que las aguas trajeron y, si se cree necesario, se remodelan las orillas.

Si se consultan los datos históricos se observa que las inundaciones son catástrofes naturales frecuentes en Navarra, dadas las numerosas riadas padecidas en lo que va de siglo. Desde 1980 se han catalogado trece inundaciones de cierta importancia en nuestra Comunidad y, sin duda, habrá habido algunas más de repercusiones locales (BELTRÁN, F., y PEJENAUTE, J., 1995). De entre todas ellas, las de octubre de 1992, objeto de este estudio, son las más representativas del tipo de riadas de otoño-invierno, que son las que más daños provocan en nuestro territorio y a la vez las de mayor frecuencia. El objetivo de este artículo es el estudio de estas inundaciones, analizando las causas, repercusiones, intensidad, áreas afectadas y zonas de mayor riesgo. Los resultados, tanto de la dinámica atmosférica como de la cantidad caída y nivel de agua de los ríos, se comparan con las últimas inundaciones de diciembre de 1992 y 1993.

Para su estudio se han utilizado los siguientes materiales ${ }^{1}$. Con respecto a la dinámica atmosférica se han consultado los mapas del tiempo de superficie y topografias de 500 y 300 milibares del Boletín Metereológico Diario elaborados por el Instituto Nacional de Meteorología y los radio sondeos de Zaragoza realizados a las $00 \mathrm{~h}$. y $12 \mathrm{~h}$. También se han analizado los siguientes datos facilitados atentamente en la sección de climatología y suelos del servicio de Estructuras Agrarias de Gobierno de Navarra. En primer lugar, las tarjetas mensuales de precipitaciones correspondientes a más de veinte observatorios navarros, representativos de las comarcas afectadas. En segundo lugar, las precipitaciones diarias, de hora en hora, correspondientes a las estaciones automáticas de Roncesvalles e Irabia, observatorios ubicados en las áreas donde tuvieron lugar las fuertes lluvias. Y, finalmente, las series históricas de precipitación de octubre, años 1941-90, en los observatorios de Artikutza, Santesteban, Eugi, Abaurrea Alta y Alsasua que se dibujan en los gráficos 18 a 22, y que son los más representativos de las comarcas navarras.

Tengo que agradecer a Antonio Gordo, jefe de Predicción del Centro Meteorológico Zonal del Ebro los datos aportados de los radio sondeos; a Francho Beltrán Audera, Meteorólogo del Servicio de Estructuras Agrarias del Gobierno de Navarra, los datos suministrados sobre los observatorios navarros; y a César Ferrer Castillo, jefe del Servicio del Control del Dominio Público Hidráulico de la Confederación Hidrográfica del Ebro y a Alberto Cañada Juste la facilitación de los datos sobre el caudal medio de las estaciones de aforo. 
Además, se han estudiado los datos de los caudales medios diarios y extremos de los días correspondientes a las tres riadas consideradas (días 3 a 10 de octubre de 1992, días 5 a 12 de diciembre de 1992, y días 23 a 28 de diciembre de 1993) de las estaciones de aforo de Aribe (río Irati), Liédena (río Irati), Eugi (río Arga), Huarte (río Arga) y Funes (río Arga), facilitados por la Confederación Hidrográfica del Ebro.

\section{LA FORMACIÓN DE LA POTENTE BORRASCA Y SUS FASES}

Para poder realizar un estudio más detallado y preciso se ha dividido este período en tres partes. En la primera, que comprende los días uno y dos de octubre de 1992, se crean los mecanismos oportunos que darán lugar posteriormente a las intensas lluvias padecidas. En la segunda o período culminante, que se extiende desde el día tres hasta el seis, tienen lugar las fuertes precipitaciones torrenciales que provocan la salida de los ríos de su cauce y las inundaciones acaecidas en Navarra. Finalmente, en la tercera y última, cesan los mecanismos desencadenantes de la tromba de agua, con lo que finaliza el proceso.

\subsection{Una potente borrasca se forma en Islandia}

La dinámica atmosférica que tiene lugar durante los citados días explica las altas precipitaciones producidas en nuestra Comunidad. En esta fase inicial se va a formar una potente área depresionaria de fuerte gradiente que, de momento, no va a afectar a Navarra.

El día uno de octubre (mapa 1) se observa una débil corriente del Oeste en Navarra con una temperatura entre los doce y los dieciséis grados bajo cero en la topografía de $\mathbf{5 0 0}$ milibares. Una depresión débil se sitúa al Oeste de Portugal, junto al paralelo $35^{\circ}$. Ningún indicio próximo a nuestras latitudes señala inestabilidad inmediata. Sin embargo, al Suroeste de Islandia, junto al paralelo $60^{\circ}$, se forma una potente borrasca que ejerce su radio de acción sobre las Islas Británicas.

En la topografía de 300 milibares (mapa 1) la depresión del Atlántico se ve coronada por un anticiclón. La corriente en chorro es fuerte del WNW, en las Islas Británicas y la borrasca principal aparece bien dibujada en idéntica posición y con orientación NW-SE. 

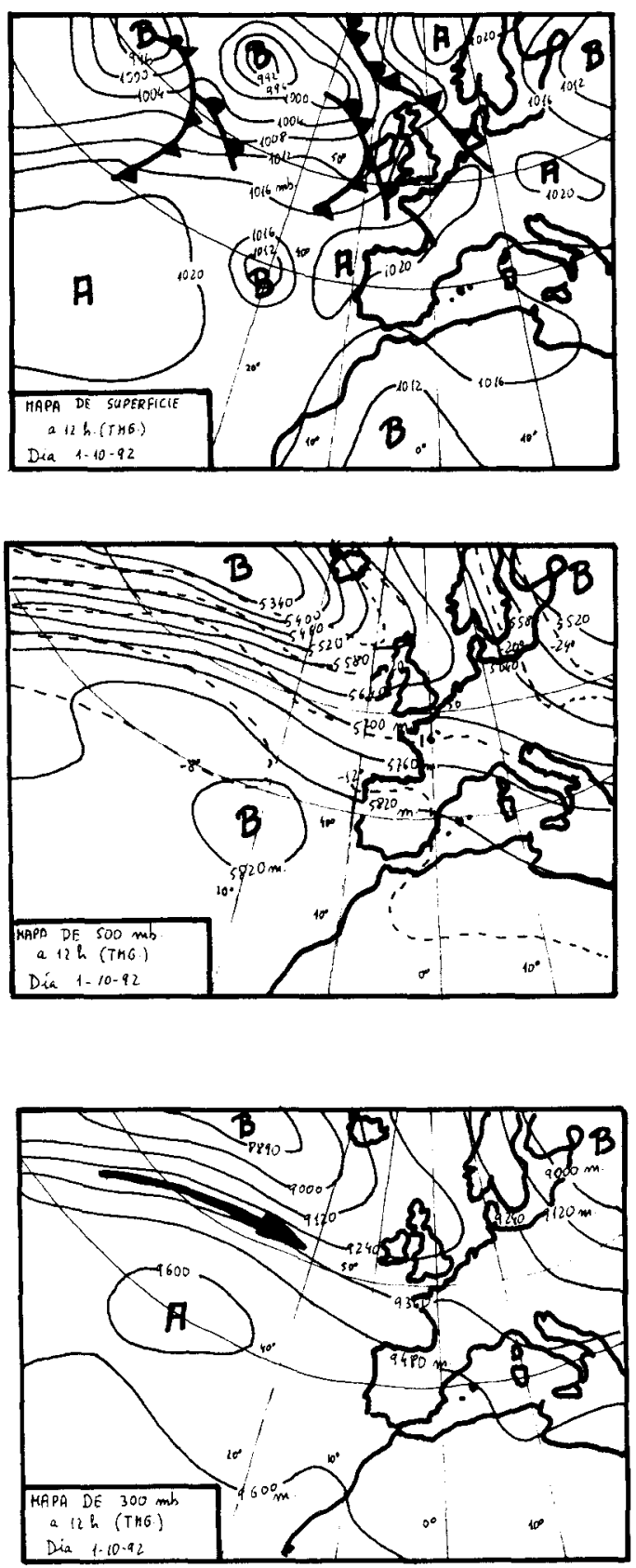

Mapa 1. 
En superficie, la situación es anticiclónica en Navarra debido a la presencia de altas presiones, próximas al golfo de Vizcaya. Varios sistemas frontales circulan zonalmente, al abrigo de la borrasca de Islandia, siguiendo una ruta septentrional próxima al paralelo $50^{\circ}$. Estos frentes no afectan a Navarra por su lejanía y producen precipitaciones en las Islas Británicas y en el Oeste de Francia. Posteriormente, el anticiclón va desapareciendo y un frente frío débil atraviesa la Comunidad dejando lluvias inapreciables en los Valles Cantábricos (Leitza ipáginas, Bera ipáginas, Lekaroz $0,4 \mathrm{~mm}$.).

El día dos, la circulación en altura se ondula y la potente borrasca situada en las inmediaciones de Islandia se profundiza y se traslada al Noroeste de Escocia. En la topografía de 500 milibares (mapa 2) una dorsal se extiende meridianamente por el Atlántico y un área de bajas presiones se profundiza por Europa occidental. Ambos centros de acción, dorsal y vaguada, envían masas de aire inestables de componente Noroeste y la temperatura sobre nuestra vertical se sitúa próxima a los dieciséis grados bajo cero. En la topografía de 300 milibares (mapa 2) la situación es similar: la corriente en chorro sigue el camino marcado por los centros de acción y llega a Navarra del Noroeste, aumentando notablemente la inestabilidad.

En el mapa de superficie (mapa 2) se observa la presencia de una fuerte borrasca en el Norte de Escocia, con varios sistemas frontales asociados, cuyos extremos entran por el Cantábrico oriental y atraviesan Navarra. Poco a poco, las masas de aire que circulan por el flanco oriental de anticiclón del Atlántico se van haciendo del Noroeste y posteriormente del Norte, lo que conlleva un aumento de la inestabilidad y la retirada del anticiclón hacia el interior del Atlántico.

Con este cambio de situación, llueve en Cantabria, el País Vasco y en nuestra Comunidad las mayores precipitaciones tienen lugar en los Valles Cantábricos y Pirenaicos, sobre todo, en los observatorios situados junto a los macizos de Cinco Villas y Quinto Real, y en los lugares elevados de los Pirineos (Artikutza 17,8 mm., Leitza 22 mm., Bera 18,2 mm., Arizkun 18 $\mathrm{mm}$., Roncesvalles $28,6 \mathrm{~mm}$., Orbaitzeta $16 \mathrm{~mm}$.). Llueve también, pero con menor intensidad y en casi todos los casos por debajo de los diez milímetros, en el resto de los observatorios de los Valles Cantábricos y Pirenaicos, peor orientados al flujo dominante y en el Corredor del Arakil y la Cuenca de Pamplona (Santesteban $9 \mathrm{~mm}$., Eugi 3,4 mm. Esparza de Salazar 3 mm., Alsasua 7 mm., Zubiri 1,5 mm., Pamplona-Obs, ipáginas). 

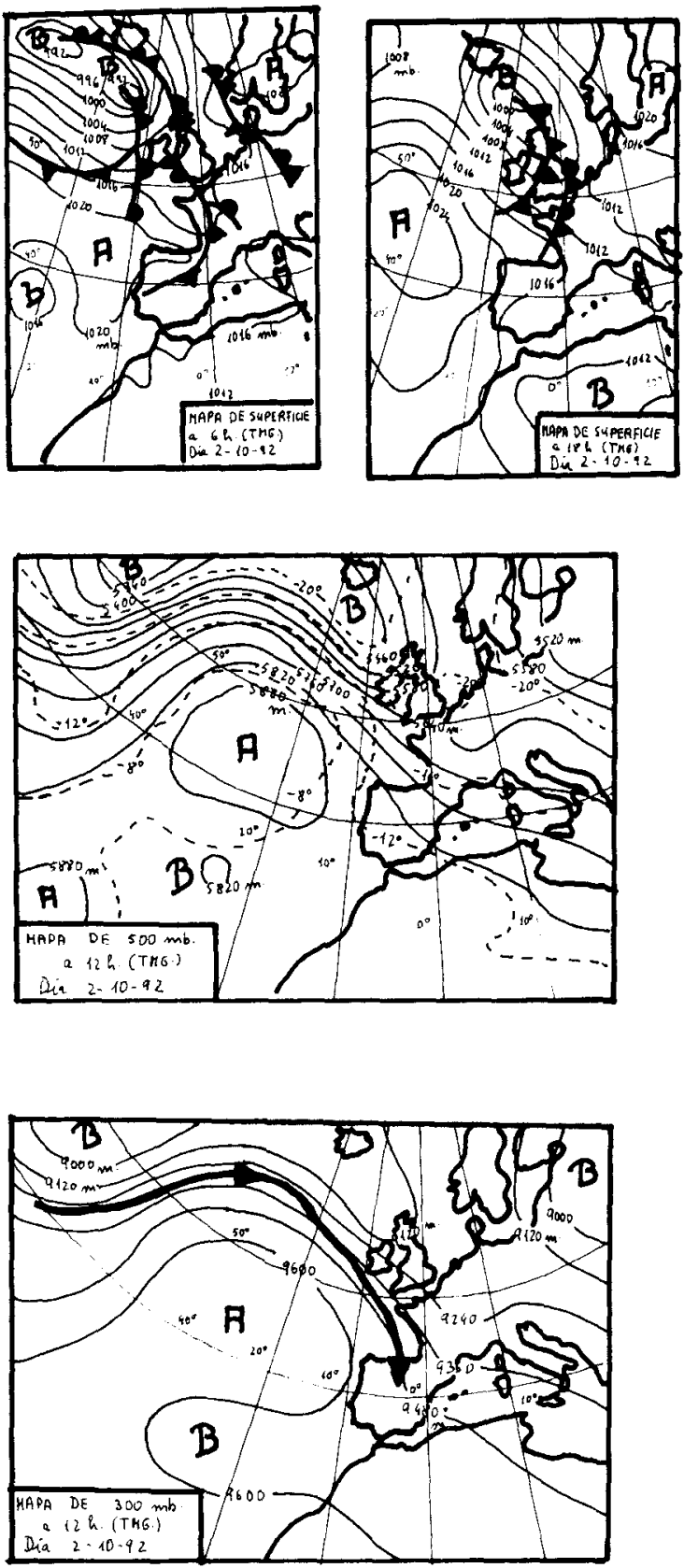

Mapa 2. 
En definitiva, en esta primera fase se ha formado la borrasca que posteriormente va a dar lugar a las fuertes precipitaciones de los días posteriores. Esta depresión se ha profundizado por las Islas Británicas y comienzan a llegar masas de aire inestables que originan las primeras lluvias. La circulación en altura se ondula y la vaguada comienza a acercarse.

\subsection{El fuerte embolsamiento frío se aproxima a Navarra}

En numerosas ocasiones se ha observado que las poderosas depresiones formadas en las inmediaciones de Islandia se trasladan zonalmente siguiendo las rutas de altas latitudes y por lo tanto, sin alcanzar sus efectos a Navarra. Pero a veces puede ocurrir, como en el caso que nos ocupa, que la borrasca se desplace desde las inmediaciones de Islandia hasta Europa occidental, aumentando ampliamente la inestabilidad en las comarcas navarras.

Esto sucedió en octubre de 1992. En efecto, el día tres en la topografía de 500 milibares (mapa 3) un embolsamiento frío se sitúa en el Norte de Francia y se extiende submeridianamente desde las Islas Británicas hasta los golfos de León y de Génova. El Cantábrico oriental y Navarra reciben por un flanco occidental masas de aire del NNW, marítimo polares, que se han humedecido abundantemente por el Atlántico y que, al llegar con gran rapidez, conservan las características frías e inestables que tenían. La temperatura en esta altura se sitúa entre los doce y dieciséis grados bajo cero y, si bien es baja, todavía no lo suficiente para que se puedan producir ascensiones violentas que desencadenen a fuertes lluvias.

En la topografía de 300 milibares (mapa 3), la situación atmosférica es muy parecida a la anterior. Una cresta de altas presiones se extiende por el Atlántico hasta las proximidades de Islandia y un talweg se centra en el Canal de la Mancha. Entre ambos centros de acción circulan masas de aire de componente NNW que llegan a Navarra con gran rapidez de traslación. La corriente en chorro es del NNW en Navarra.

En el mapa de superficie a las $6 \mathrm{~h}$. (mapa 3), un área de bajas presiones se coloca en las proximidades de París, mientras el anticiclón del Atlántico se sitúa al Oeste de Galicia. Ambos centros de acción, anticiclón y borrasca, atraen hacia Navarra masas de aire de componente Norte que, acompañadas de frentes fríos, atraviesan la Península. Doce horas después, a las $18 \mathrm{~h}$., la borrasca se centra en Córcega y engloba a Navarra 

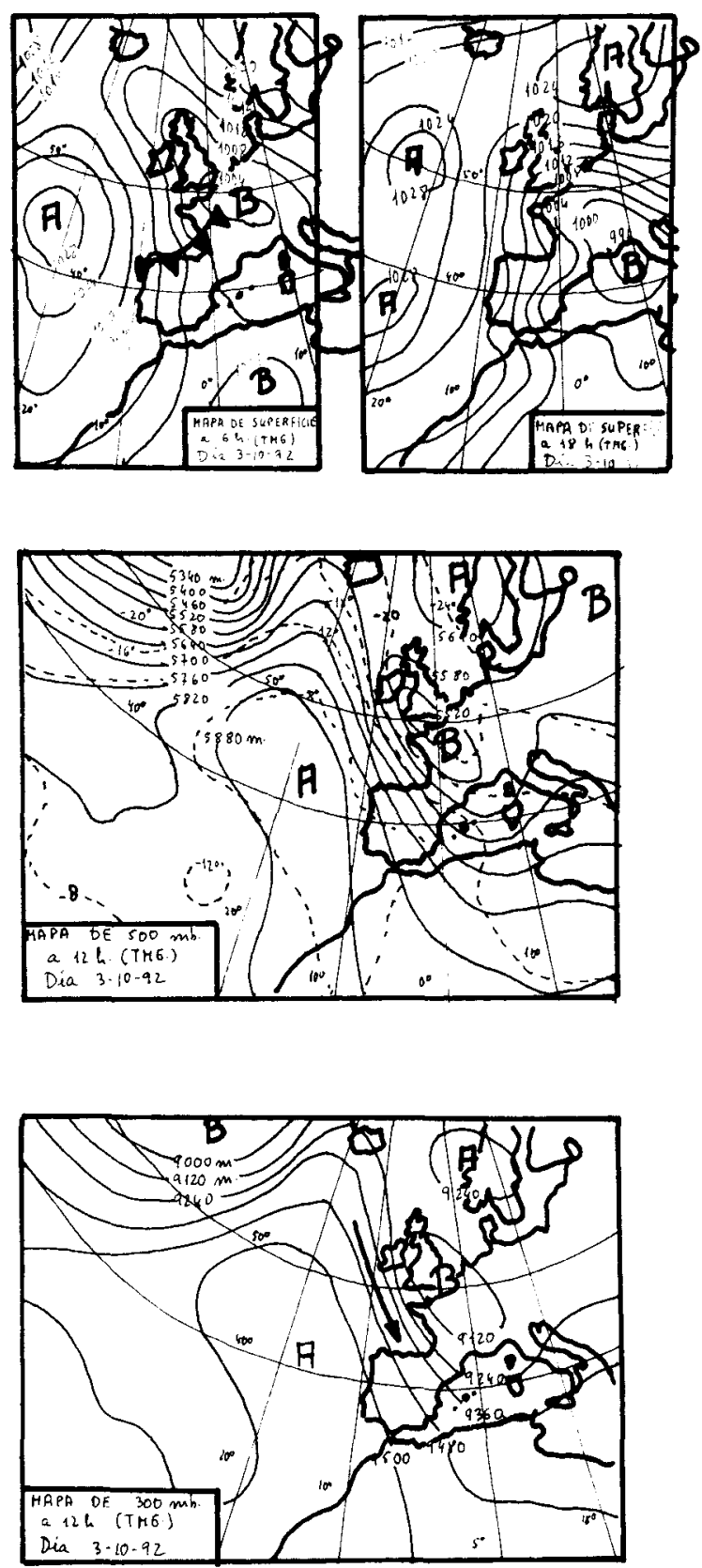

Mapa 3. 
por su flanco occidental. El gradiente de presión es fuerte, lo que hace aumentar la velocidad de traslación de las masas de aire.

En el radio sondeo de Zaragoza correspondiente al día tres de octubre a las $00 \mathrm{~h}$. (gráfico 1) se observa inestabilidad convectiva ante los estratos siguientes: 841-797 mb., 702-638 mb., 570-533 mb. y 422-414 mb.; hay viento fuerte del WNW, en niveles altos. Doce horas después, en el radio sondeo realizado a las $12 \mathrm{~h}$. (gráfico 2) existe inestabilidad absoluta y convectiva entre los siguientes estratos: $997-935 \mathrm{mb}$., $850-700 \mathrm{mb}$., 624-620 mb., 595-578 mb., 300-279 mb., 203-163 mb- El viento es fuerte de componente NW en las altas capas.

Hay una serie de factores que favorecen la consecución de elevadas precipitaciones en Navarra: la presencia de aire frío en altura, la proximidad a la borrasca, la llegada de masas de aire marítimo polares, recalentadas conforme llegan a nuestras latitudes y las violentas ascensiones.

En los Valles Cantábricos llueve el día tres con gran intensidad, destacando sobre todo la precipitación registrada en los observatorios situados junto al macizo de Cinco Villas en los Valles del Urumea-Añarbe y Leitzarán (Artikutza 117, $8 \mathrm{~mm}$., Leitza $95 \mathrm{~mm}$.). En el resto de los Valles Cantábricos la cantidad recogida, si bien inferior a la medida en los observatorios anteriores, es sumamente elevada (Betelu $67 \mathrm{~mm}$., Bera 45,7 mm., Santesteban 75,8 mm., Lekaroz $49 \mathrm{~mm}$., Arizkun $56 \mathrm{~mm}$.). Es de destacar el papel de pantalla pluviométrica que realiza el macizo de Cinco Villas con situaciones de primer y cuarto cuadrante.

Los Valles Pirenaicos, sobre todo los centrales resultan también muy lluviosos, aunque la cantidad recogida es inferior a la registrada en los
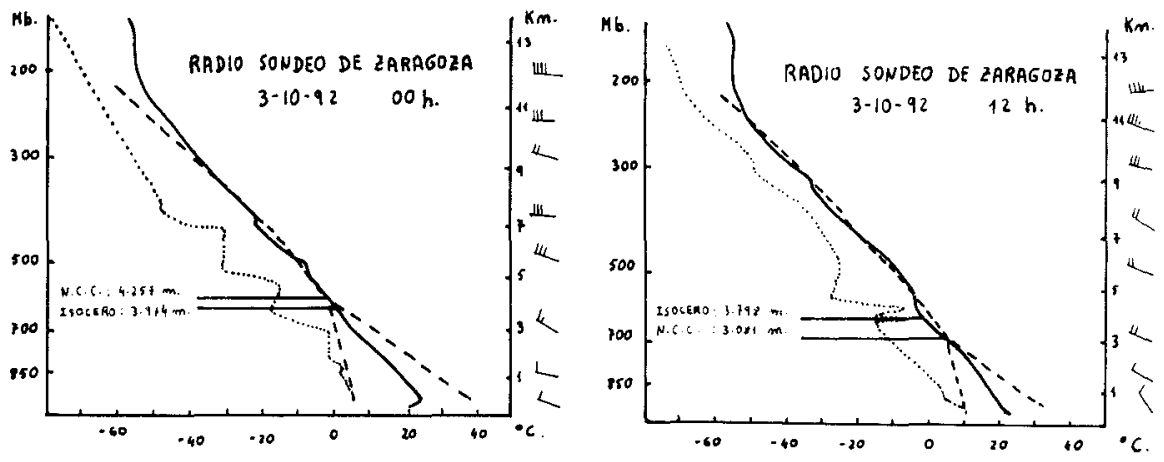

Gráficos 1 y 2. 
Valles Cantábricos. Hay que destacar las estaciones situadas junto al macizo de Quinto Real, auténtica pantalla condensadora de humedad que aumenta sensiblemente la operatividad de las masas de aire inestables de componente Norte y Noroeste (Roncesvalles $84 \mathrm{~mm}$., Valcarlos 53,6 mm., Eugi $60,5 \mathrm{~mm}$.). También resultó muy irrigado el observatorio de Orbaitzeta (74 mm.), situado a barlovento del murallón de la Sierra de Abodi. Las precipitaciones descendieron, si bien todavía fueron intensas, hacia el Sur y el Este por el efecto pantalla que los Pirineos van realizando conforme se llega a la parte oriental (Abaurrea Alta, $27 \mathrm{~mm}$.; Aribe, $47 \mathrm{~mm}$.; Esparza de Salazar, 54 mm.; Navascués, 19,5 mm.; Urzainqui, 36,5 mm.).

Finalmente, hay que citar la importancia que tuvieron las precipitaciones en otras zonas marginales a las anteriores, como son los Valles de Larraun, Goñi y Améscoa Baja y el Corredor del Arakil (Alli, 70,2 mm.; Larraona, $47 \mathrm{~mm}$; Goñi, 53,6 mm.; Alsasua, 51,5 mm.). Es importante resaltar el papel de pantalla pluviométrica de algunas montañas navarras (Sierras de Aralar, Urbasa, Andía y Lóquiz) con masas de aire de componente Norte.

En los gráficos 3 y 4 se observan la precipitaciones caídas durante todo el día tres de octubre. En el observatorio de Roncesvalles la lluvia estuvo presente en casi toda la jornada con más fuerza entre las cinco y las diez de la mañana en que se recogieron $32,2 \mathrm{~mm}$., y entre las diecinueve

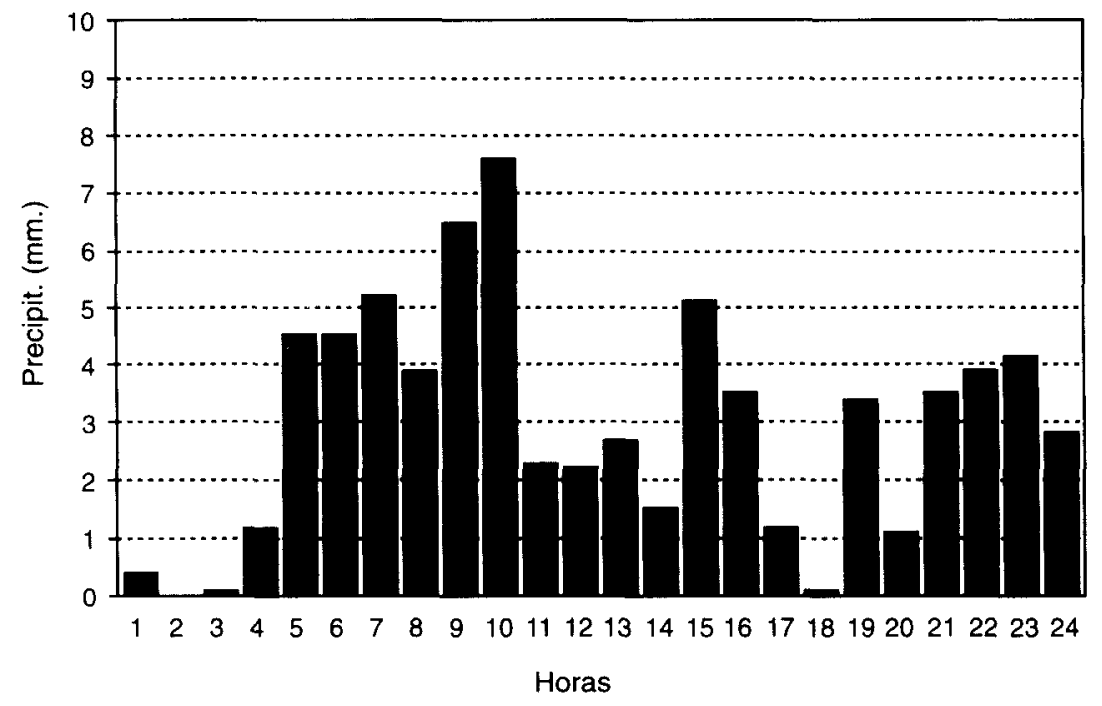

Grático 3. Roncesvalles. Precipitaciones dia 3-10-92. 


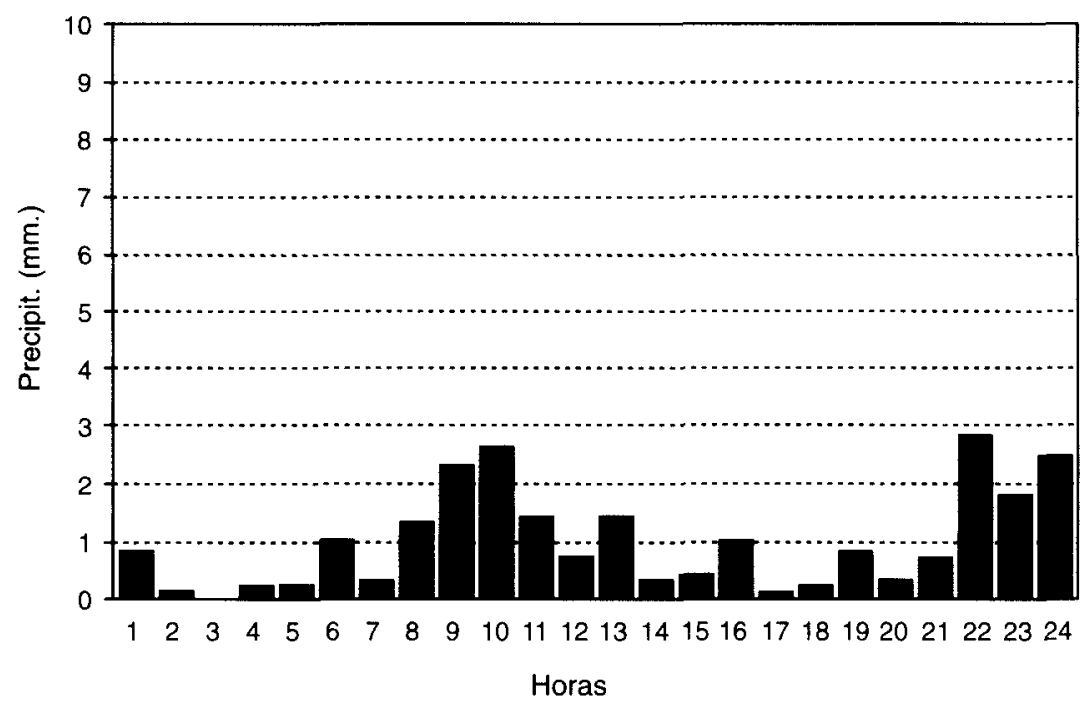

Gráfico 4. Irabia. Precipitaciones día 3-10-92.

y veinticuatro horas en que se midieron $18,8 \mathrm{~mm}$. En total se anotaron $71,3 \mathrm{~mm}$. en todo el día.

En Irabia ese mismo día (gráfico 4) se recogieron $23,2 \mathrm{~mm}$. de precipitación, muy repartida entre toda la jornada con dos momentos de mayor intensidad entre las ocho y las trece horas, que se anotaron $9,7 \mathrm{~mm}$. y entre las veintiuno y veinticuatro horas que se midieron $7,8 \mathrm{~mm}$. Por 10 tanto, precipitaciones más altas en Roncesvalles, observatorio mejor situado con respecto al frente de ataque de las corrientes perturbadas.

El día cuatro se intensifican las precipitaciones y se alcanzan valores intensos en algunas comarcas navarras. En la topografía de 500 milibares (mapa 4) se observa que la vaguada que seguía la vía Islandia-Islas Británicas-Sudeste de Francia, se ha desprendido de la circulación general y ha dado lugar a una gota fría, cuyo centro se sitúa junto a las costas catalanas. La temperatura en esia altura es de veinte grados bajo cero, valor muy bajo para la estación otoñal, por lo que se trata de un potente embolsamiento frío capaz de dar lugar a nubes de fuerte desarrollo vertical. La orientación de la baja fría, NE-SW, permite la llegada a Navarra de masas de aire de componente Norte, que vienen desde Islandia, con amplio recorrido por el Atlántico.

Se trata de masas de aire húmedas, porque se han cargado de humedad en su largo recorrido por el Atlántico, e inestables porque se van recalentando 
por su base conforme se aproximan a Navarra. La presión es muy baja, dado que los 500 milibares se obtienen a una altura de $5.580 \mathrm{~m}$. y el gradiente es elevado, pues la Comunidad se encuentra entre la altura citada y los $5.520 \mathrm{~m}$. La posición de Navarra, al Oeste del embolsamiento frío; es decir, en el frente de ataque es la idónea para conseguir fuerte inestabilidad. En la topografía de 300 milibares (mapa 4), la borrasca es bien visible en idéntica posición. La corriente en chorro es fuerte y del Norte y Navarra se encuentra entre los 9.240 m. y los $9.120 \mathrm{~m}$., por lo que la inestabilidad es elevada también en este nivel.

En los mapas de superficie correspondientes al día cuatro, la situación es muy parecida, tanto a las seis de la mañana como a las seis de la tarde (mapa 4). El centro de la borrasca, fiel reflejo de la situación en altura, se sitúa en el Sudeste de Francia y engloba a Navarra por su flanco occidental. Masas de aire de componente Norte atraviesan nuestro territorio con rapidez. La presión es baja por la proximidad a la borrasca y el gradiente de presión elevado.

La situación inestable en superficie y altura propician la presencia de elevadas Iluvias en Navarra. En los Valles Cantábricos llueve con fuerte intensidad, aumentando considerablemente el caudal de los ríos. Destacan las precipitaciones registradas en el Valle de Leitzarán que superan los cien milímetros (Leitza $112 \mathrm{~mm}$.). El resto de los observatorios resulta muy lluvioso y en todos los casos se superan los cincuenta milímetros (Artikutza $78,7 \mathrm{~mm}$., Betelu $73 \mathrm{~mm}$., Arizkun $78 \mathrm{~mm}$.). En las partes más protegidas de la Regata del Bidasoa las precipitaciones, si bien son altas, son inferiores (Bera 50,3 mm., Santesteban 50,7 mm.). La situación de estos valles y la presencia de las montañas del Norte de Navarra explican estos resultados.

Los Valles Pirenaicos son también muy lluviosos y superan los cuarenta milímetros en todos los observatorios. El más lluvioso es Orbaitzeta que se sitúa por encima de los cien milímetros por su situación al pie de la Sierra de Abodi (Orbaitzeta $108 \mathrm{~mm}$.). Los Pirineos Centrales resultan más Iluviosos que los Orientales (Roncesvalles $72 \mathrm{~mm}$., Eugi $77 \mathrm{~mm}$., Aribe 57 mm., Esparza de Salazar 56, $8 \mathrm{~mm}$. Urzainqui $45 \mathrm{~mm}$.). Si nos alejamos de las cabeceras de los valles, las lluvias disminuyen (Navascués $33 \mathrm{~mm}$.). Es cierto que los Pirineos navarros por su menor altitud no son un obstáculo para que se registren fuertes precipitaciones de componente Norte cuando las condiciones son favorables.

Otras zonas muy lluviosas fueron los Valles de Larraun, Arakil, Esteribar, Goñi y Amescoa Baja (Alli, $110 \mathrm{~mm}$.; Alsasua, 59,5 mm.; 

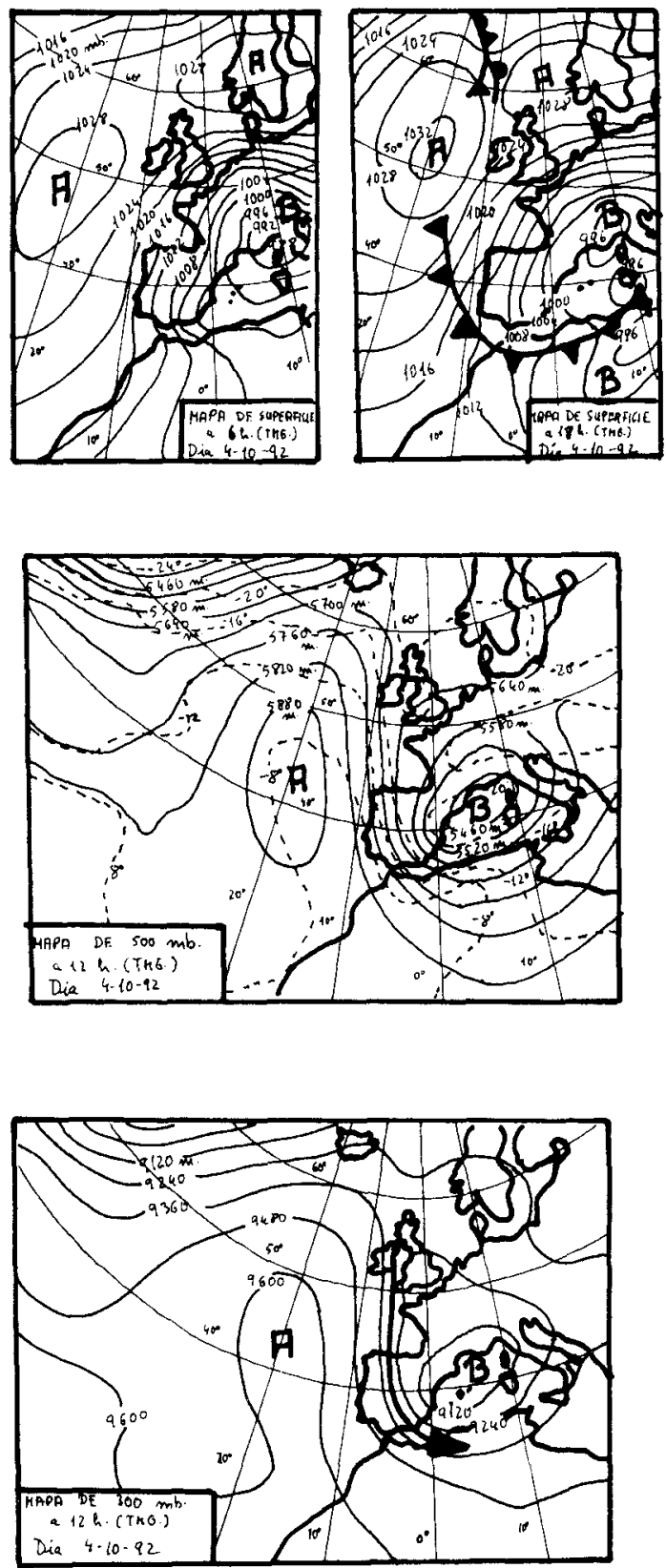

Mapa 4. 


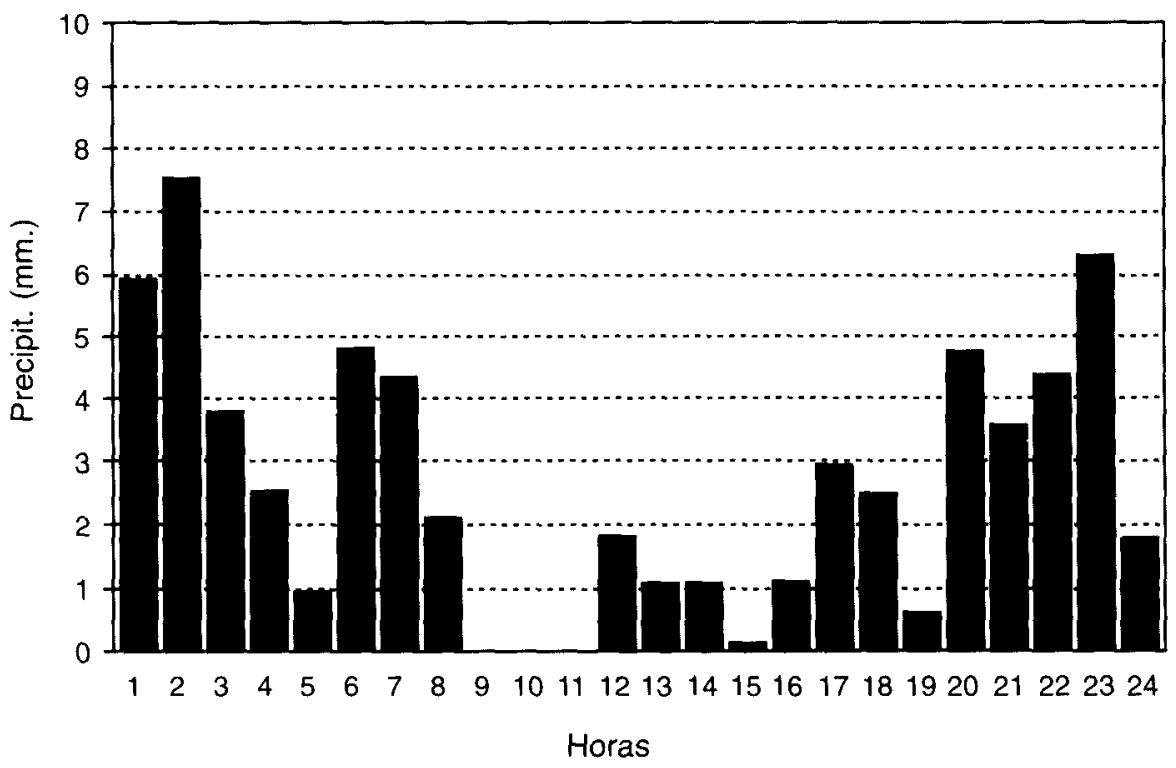

Gráfico 5. Roncesvalles. Precipitaciones día 4-10-92.

Zubiri, $60 \mathrm{~mm}$.; Goñi, $61,9 \mathrm{~mm}$.; Larraona, $30 \mathrm{~mm}$.). Se trata de observatorios situados junto a montañas importantes que activan la condensación (Sierra de Aralar, complejo montañoso Urbasa-Andía, Sierra de Lóquiz).

En el gráfico 5 se observa la lluvia durante el día cuatro. En esta jornada se recogieron setenta y dos milímetros de precipitación. Las máximas lluvias se dieron en dos períodos: el primero entre la una y las ocho de la madrugada $(31,8 \mathrm{~mm}$.) y el segundo entre las veinte y las veinticuatro horas $(21,5 \mathrm{~mm}$.). El resto del día fue menos lluvioso. Por lo tanto, bastante intensidad en esos intervalos, lo que dio lugar a la fuerte subida de los ríos de la zona.

En el gráfico 6 se aprecia las precipitaciones de Irabia durante el citado día $(54,7 \mathrm{~mm}$.). Las más fuertes lluvias tuvieron lugar entre las veintiuno y veintitrés horas en las que se recogieron $20,2 \mathrm{~mm}$., lo que originó una subida fuerte en el pantano de Irabia. Altas lluvias también se produjeron entre la una y las ocho de la madrugada en que se midieron 22,9 $\mathrm{mm}$.

El día cinco de octubre persiste la alta inestabilidad y continúan las elevadas precipitaciones, que sumadas a las anteriores dan lugar a las 


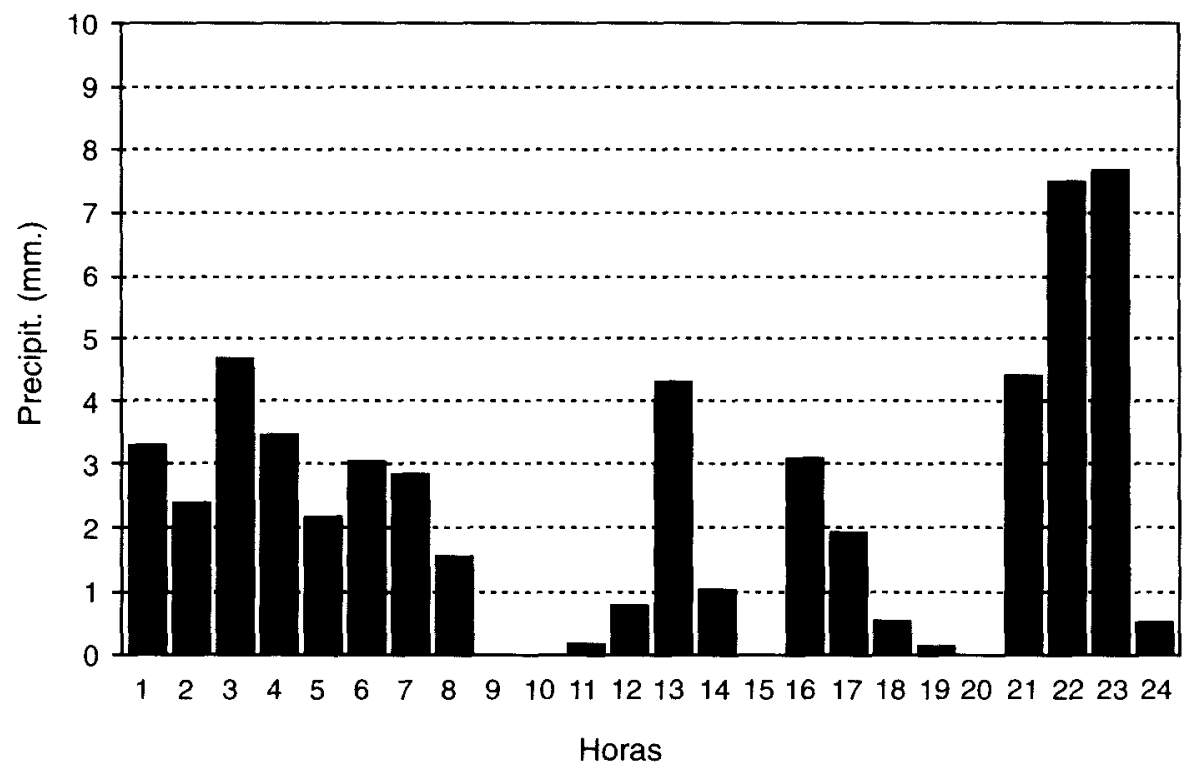

Gráfico 6. Irabia. Precipitaciones dia 4-10-92.

inundaciones. Es el día en que mayores lluvias se van a registrar en la mayor parte de los observatorios navarros, debidas a la circulación de la atmósfera de este día, favorable a la presencia de intensas precipitaciones.

En el mapa de 500 milibares (mapa 5) se observa que la baja fría se centra al Este de Cataluña, abarca toda la Peninsula y engloba a Navarra por su flanco occidental. La temperatura en esta altura se sitúa por debajo de los dieciséis grados bajo cero, por lo que el frío en altura y por lo tanto, la inestabilidad siguen presentes. La situación es parecida en la topografía de 300 milibares (mapa 5). La borrasca de niveles altos, todavía poderosa, se centra en el Mediterráneo occidental y la corriente en chorro la rodea por el lado occidental, siendo del Noroeste en Galicia.

En los mapas de superficie, seis y dieciocho horas, se hace patente también la inestabilidad (mapa 5). La borrasca se sitúa en el golfo de Génova (996 milibares) y por su flanco occidental llegan masas de aire de componente NNE, que circulan a gran velocidad y van acompañadas de frentes ocluidos. El gradiente de presión es acusado, ya que la Península se encuentra entre los 996 milibares y los 1.016 milibares. Se puede afirmar, así pues, que se sigue en el punto culminante de la borrasca. 

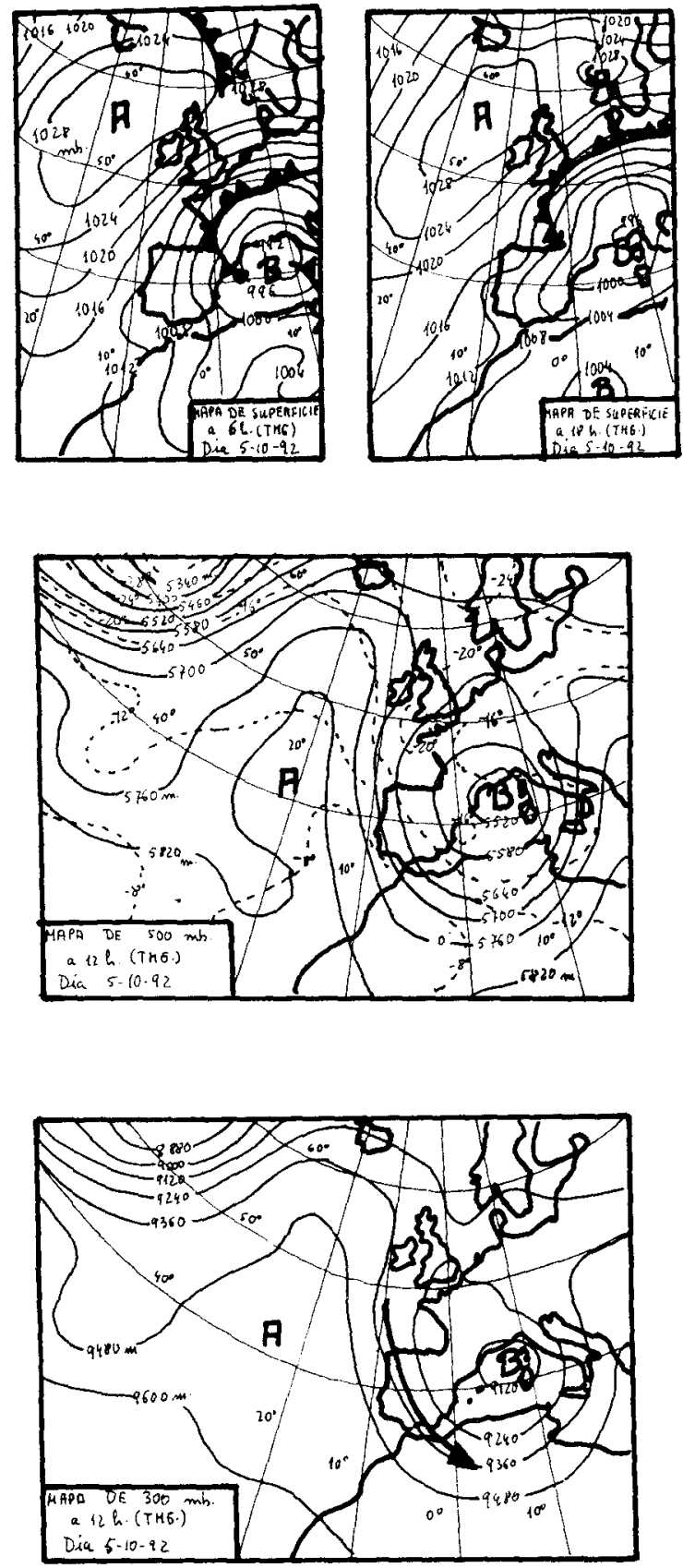

Mapa 5. 


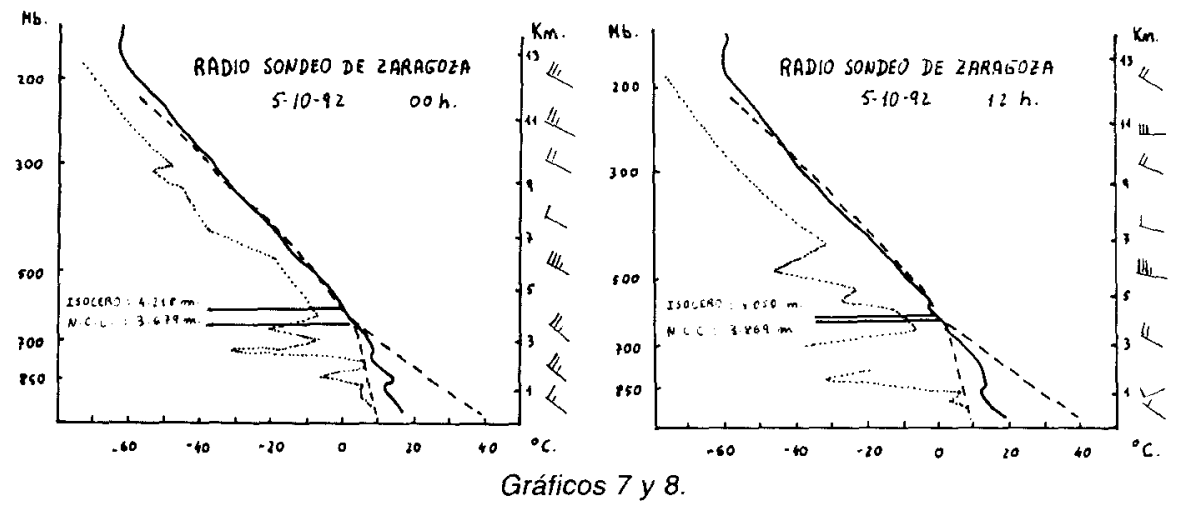

En el radiosondeo de Zaragoza del día cinco de octubre realizado a las 00 horas (gráfico 7) se observa inestabilidad convectiva entre los siguientes estratos: 996-920 mb., 865-838 mb., 817-810 mb., 782-726 mb., 700-663 mb., 471-403 mb. y 172-146 mb. Doce horas después en el efectuado a las 12 horas (gráfico 8 ) hay inestabilidad convectiva entre los siguientes estratos: 995-915 mb., 874-823 mb., 780-700 mb., 647-566 mb., 526-500 mb., 300-294 mb., y 250-200 mb. El viento es muy fuerte, sobre todo en la topografía de los 500 milibares.

La inestabilidad es bien visible también en el satélite Meteosat, en cuya imagen se observa que Navarra continúa bajo la influencia de vientos frescos del Norte con cielos muy nubosos. Asimismo se aprecia nubosidad abundante en el centro de la borrasca, situada en el Sudeste de Francia y nubes bajas, cúmulos y estratocúmulos que atraviesan Navarra, girando alrededor de la borrasca central. Los Valles Cantábricos y Pirenaicos tienen intensa nubosidad.

Las más altas precipitaciones se registraron el día cinco en la parte occidental de los Valles Cantábricos, Valle del Baztán y en las cabeceras de los Valles Centrales Pirenaicos, superando o acercándose a los cien milímetros (Artikutza 104, 6 mm., Leitza 106 mm., Arizkun 110,5 mm., Roncesvalles 132,3 mm., Eugi 92,6 mm., Orbaitzeta $131 \mathrm{~mm}$.). Estos observatorios están situados junto a pantallas condensadoras de humedad, como son los macizos de Quinto Real y Cinco Villas y la Sierra de Abodi, que hacen aumentar considerablemente las precipitaciones.

Las precipitaciones fueron elevadas, pero inferiores a las zonas anteriores, en los Valles de Araitz, Larraun, Arakil y Goñi, Regata del Bidasoa y zona de Garralda-Aribe, en donde se midieron más de cincuenta mili- 
metros, cantidad importante teniendo en cuenta la acumulación de lluvias en los dias anteriores (Betelu $78 \mathrm{~mm}$., Alli $82,3 \mathrm{~mm}$., Alsasua $66 \mathrm{~mm}$., Goñi 53,4 mm., Bera 64,5 mm., Santesteban $80 \mathrm{~mm}$., Abaurrea Alta 66 $\mathrm{mm}$., Aribe $68 \mathrm{~mm}$.).

En el gráfico 9 se puede apreciar la precipitación del día cinco en Roncesvalles. Estuvo lloviendo con bastante intensidad prácticamente toda la jornada, destacando sobre todo la cantidad caída entre las dos y las ocho de la madrugada, en que se recogieron cuarenta y nueve milímetros. Un segundo momento de fuerte precipitación sucedió entre las once y las dieciséis horas, en que casi se alcanzaron los cuarenta milimetros $(37,1 \mathrm{~mm}$.). Finalmente, entre las veintiún y las veinticuatro horas se midieron veintitrés milímetros. Por lo tanto, si a estas lluvias se añaden las de los días anteriores, es lógico que el río Urrobi experimentase una crecida elevada.

Más altas todavia fueron las precipitaciones caídas en la cabecera del rio Irati; es decir, en el observatorio de Irabia (gráfico 10). Las lluvias fueron elevadas todo el día sin interrupción. Las máximas precipitaciones se produjeron entre las tres y las ocho horas, en que se rozaron los cincuenta milímetros $(49,8 \mathrm{~mm}$.) y entre las veintiuna y veinticuatro horas en que se alcanzaron los veinticinco milímetros $(25,9 \mathrm{~mm}$.). A las cinco de la tarde, hora de máxima precipitación, se recogieron casi diez milímetros

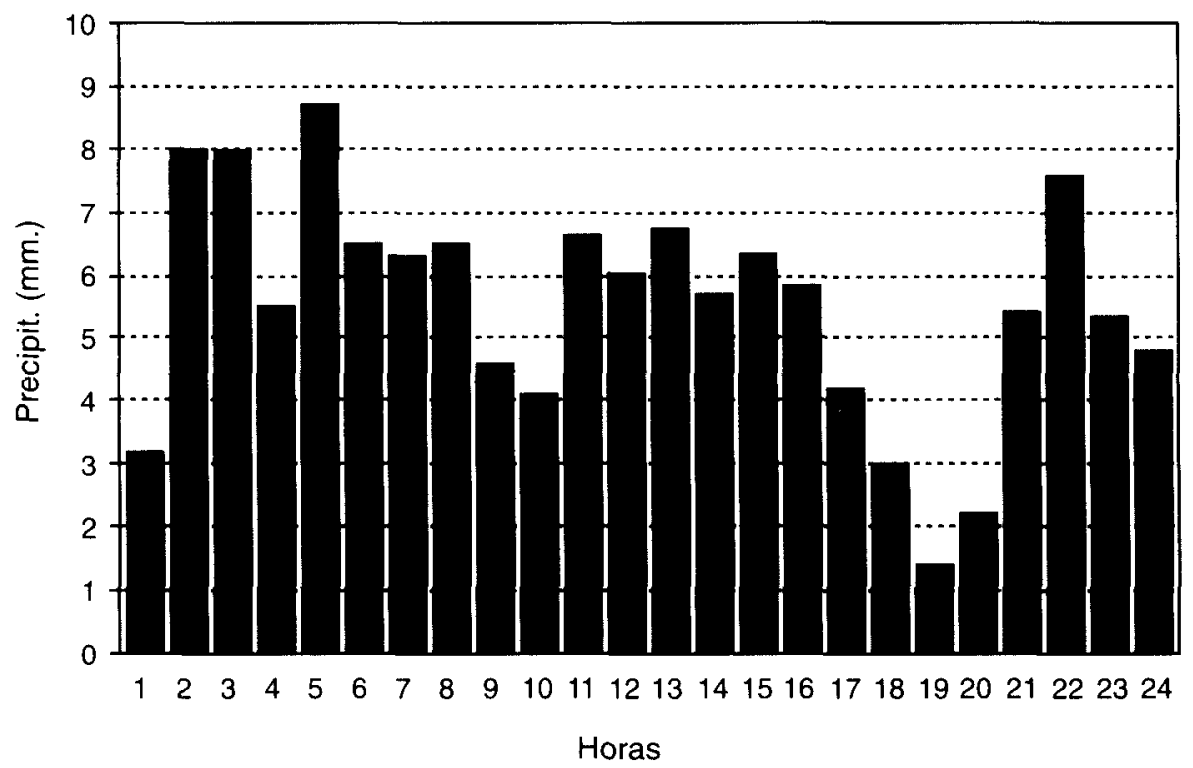

Gráfico 9. Roncesvalles. Precipitaciones día 5-10-92. 


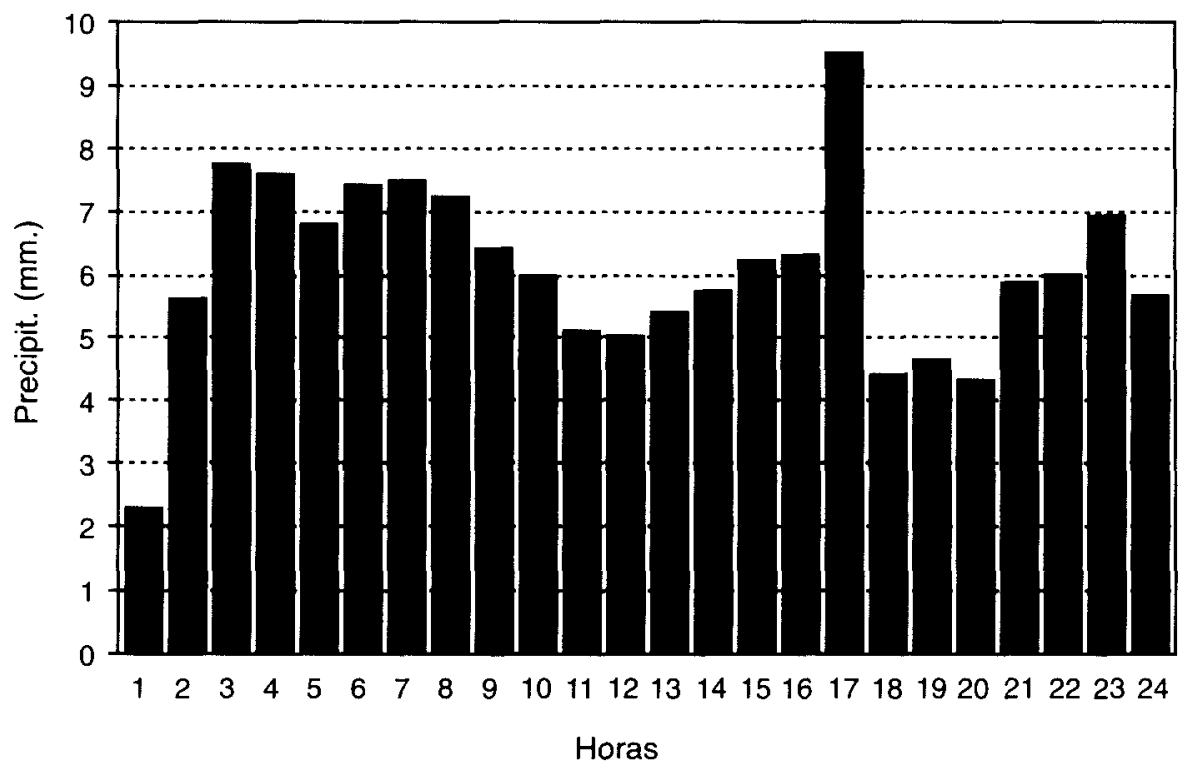

Gráfico 10. Irabia. Precipitaciones dia 5-10-92.

$(9,5 \mathrm{~mm}$.). Las precipitaciones totales durante el día llegaron a la cifra impresionante de ciento cuarenta y cinco milímetros.

A la vista de estos datos se pueden hacer las siguientes anotaciones. En primer lugar, hay que resaltar que las precipitaciones son diferentes a las estivales, ya que se consiguen altas lluvias no en pocas horas, sino a lo largo del día, pues de lo contrario las crecidas de los ríos serían instantáneas y todavía más peligrosas. En segundo lugar conviene decir que esta cantidad de lluvia, unida a la de los días anteriores, es muy elevada por lo que los ríos acaban llenando su cauce y originando intensas avenidas. Finalmente, no es de extrañar que el pantano de Irabia estuviese a rebosar y el río Irati ocasionase inundaciones en los pueblos ribereños. Las altas precipitaciones acumuladas en los últimos días dieron lugar a fuertes crecidas e inundaciones en varias zonas.

a) El primer foco de inundación se registró en los Valles Cantábricos. Los ríos Araxes, Leitzarán y Urumea llevaban mucha cantidad de agua y se desbordaron en algunos puntos, dando lugar a cortes en las carreteras próximas a Goizueta, Arribe-Atullu, Bera, Igantzi, Arantza y Beartzun. Mención especial merece el río Bidasoa que experimentó una fuerte crecida en su recorrido por el Valle de Baztán. A su paso por Elbete numero- 
sas praderas y pistas estaban anegadas. Se temió que se desbordara en Elizondo donde el agua cubrió por completo los dos ojos del puente Guiltxaurdi. En el puente Antzitonea el agua bajaba con fuerza impresionante y arrastraba árboles y ramas.

b) Un segundo foco de inundación se registró en los Pirineos Centrales y Orientales. En efecto, la cabecera de los ríos Arga, Erro, Urrobi e Irati, difícilmente podían desaguar la cantidad de agua que les cayó. Situación crítica especial atravesó el pantano de Irabia, situado en la cabecera del río Irati, que estuvo medio día en situación de alarma a consecuencia de los problemas surgidos en las compuertas de los aliviaderos, lo que provocó el desbordamiento del agua por encima de la presa. El área comprendida entre las localidades de Orbaitzeta-Orbara-Aribe fue bastante afectada, siendo anegadas las huertas y la carretera cortada en algunos tramos. Asimismo en algunos pueblos situados junto a los mencionados ríos (Erro, Espinal, Burguete, Aóiz), el agua anegó cultivos y carreteras. También las cabeceras de los ríos Salazar, Belagua y Esca en los Pirineos Orientales registraron cuantiosas lluvias y crecidas importantes en Ochagavía, Uztárroz e Isaba.

Debido a las lluvias intensas de los últimos días, el suelo de los bosques, el de los prados y el de los ríos se encontraba saturado de agua, por lo que esa cantidad de agua, al no poder ser tragada, se encaminaba pendiente abajo hacia los ríos por numerosos regueros. Conviene advertir que la vegetación es un factor importante a la hora de retener el agua cuando existen fuertes lluvias. El bosque caducifolio, extendido por los Valles Cantábricos y Pirenaicos, hizo disminuir bastante la riada en la zona de bosque, pero era tal la cantidad de agua caída que no pudo tragarla, transformándose en una auténtica esponja. Hay que resaltar en este sentido el beneficio que supone la presencia de masas boscosas de hayas y robles, pues el agua se retiene y se infiltra por las fuertes raices de estos árboles que forman una auténtica maraña que protege los suelos en caso de inundación.

Por otra parte, el bosque de coníferas abundante en estas áreas también supuso cierta retención, si bien inferior a la del bosque de frondosas, pues cuando la lluvia es abundante la capacidad de retención se colma pronto y es notablemente inferior. El papel de frenado de los pinos de repoblación, presentes en estos valles, es inferior.

c) Un tercer foco lluvioso tuvo lugar en los valles meridionales húmedos y en el Corredor del Arakil, en donde los ríos Ultzama, Arakil y Larraun 
principalmente dieron lugar a crecidas importantes en los alrededores de Alsasua e Irurtzun. La carretera nacional 130 Pamplona-San Sebastián quedó cortada entre Irurtzun y Urritza al desbordarse el río Larraun junto a las obras de la autovía.

También es preciso considerar el papel de los prados muy abundantes sobre todo en los Valles Cantábricos y meridionales húmedos cuando caen intensas lluvias. Las numerosas y pequeñas raices de las hierbas, cuando las lluvias no son muy fuertes, retienen bien el suelo y favorecen la filtración del agua hasta capas más profundas, alimentando los acuíferos. El problema viene cuando las precipitaciones son excepcionales como las del caso que nos ocupa. Entonces la capacidad de absorción se supera enseguida, el agua no es retenida y se traslada ladera abajo, y si está muy empapada, pueden deslizarse las tierras formando barrancos. Éste es un riesgo que se da con las lluvias torrenciales, favoreciendo la pendiente este proceso.

d) La capital navarra registró también los efectos del temporal. El río Arga alcanzó las huertas de la Rochapea y de la Magdalena y afectó a las obras de construcción de los puentes de Aranzadi y de la Rochapea. La zona del Vergel y las inmediaciones de la Magdalena y de la Rochapea fueron anegadas por las aguas. El impacto de las inundaciones suele ser mayor en las ciudades. En Pamplona en las inundaciones de octubre de 1992 se anegaron algunas zonas de la Rochapea y la Magdalena. Hay que tener en cuenta que los bosques y las praderas en el campo suponen una protección ante las fuertes lluvias. Sin embargo, el suelo de hormigón y de asfalto de la ciudad es totalmente impermeable y el agua desaparece por el sistema de alcantarillado, que está diseñado para dar salida a precipitaciones normales. Ahora bien, cuando las Iluvias son excepcionales las alcantarillas se ven insuficientes, se llenan y se convierten en auténticos surtidores por los que sale el agua con fuerza.

\subsection{El fin del temporal de lluvias}

Los dias seis y siete de octubre significaron el final de la borrasca. En efecto, las precipitaciones fueron disminuyendo, si bien todavía se mantuvieron registros importantes en algunos observatorios, y las inundaciones remitieron, volviendo, poco a poco los ríos a sus cauces.

En el mapa de 500 milibares del día seis (mapa 6) se aprecia cómo la borrasca con centro en el Este de Francia y que abarca toda la Península, 

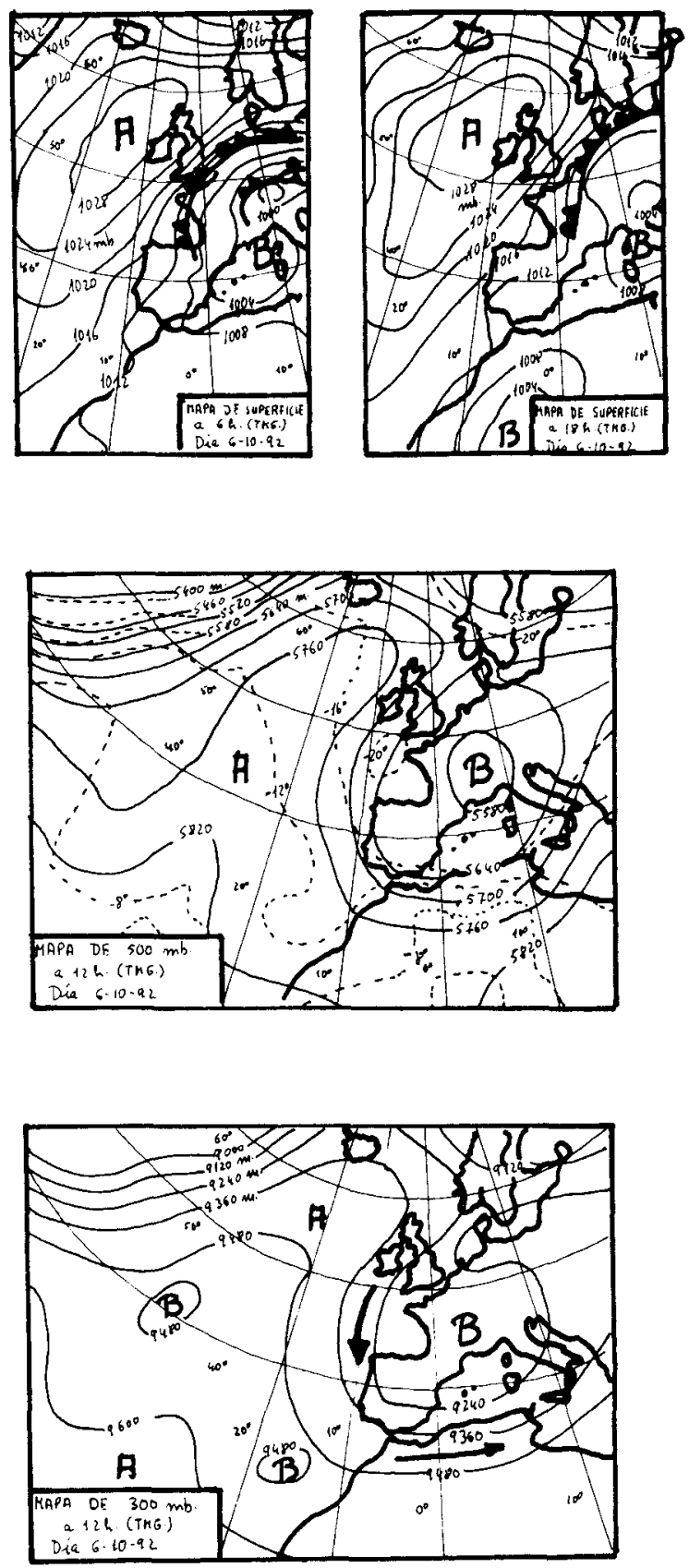

Mapa 6. 


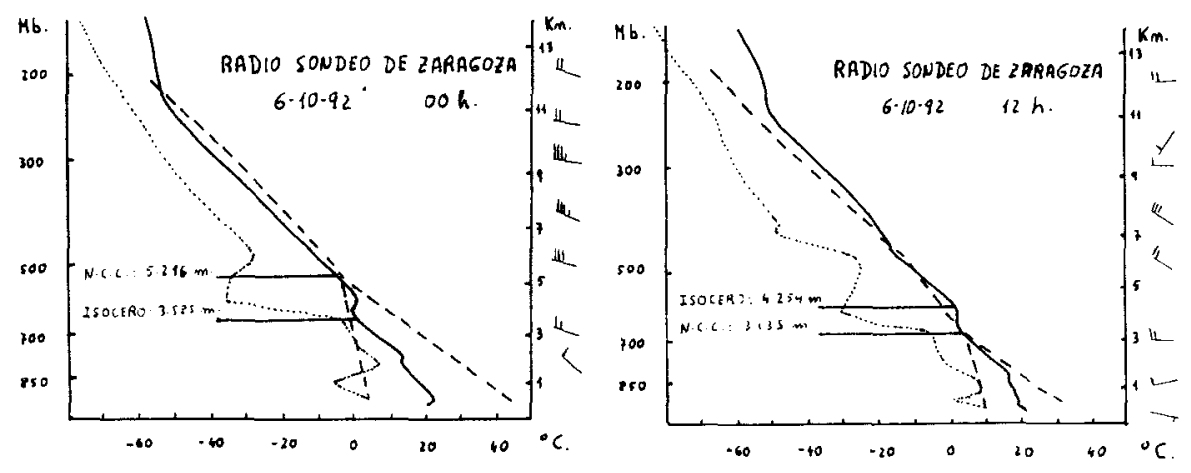

Gráficos 11 y 12 .

no es tan potente y se está rellenando. Por otra parte, Navarra se encuentra dentro de la isoterma de dieciséis grados bajo cero, por lo que el frío y la inestabilidad en altura van remitiendo. Algo parecido sucede en la topografía de 300 milibares (mapa 6) en que Navarra se encuentra dentro del radio de acción de la borrasca y comprendida dentro de la isohipsa $9.240 \mathrm{~m}$. La corriente en chorro, del Norte en Galicia y del Este en Gibraltar, rodea la Península.

En los mapas de superficie de las seis de la mañana y de las seis de la tarde se observa una situación del NNE, todavía de fuerte gradiente. Navarra se encuentra en ambos casos entre un anticiclón centrado al Oeste de Irlanda y una depresión situada en el Centro de Europa. Ambos centros de acción dirigen sobre nuestra Comunidad aire inestable de componente Norte acompañado de sistemas frontales ocluidos. Aunque la situación es parecida, en un intervalo de doce horas se aprecia una tendencia hacia la mejoría, pues el gradiente bárico disminuye y la presión aumenta sensiblemente.

En la radio sondeo de Zaragoza del día seis a las cero horas (gráfico 11) se puede observar inversión e inestabilidad convectiva entre los estratos 992 mb-866 mb Inestabilidad convectiva entre los estratos $813 \mathrm{mb}-629 \mathrm{mb}$ e inversión e inestabilidad convectiva entre los $629 \mathrm{mb}-599 \mathrm{mb}$. En el radio sondeo de las doce horas (gráfico 12) se aprecia inestabilidad absoluta entre los estratos $992 \mathrm{mb}-965 \mathrm{mb}$, inestabilidad convectiva entre los siguientes estratos: $894 \mathrm{mb}-775 \mathrm{mb}, 669 \mathrm{mb}-647 \mathrm{mb}, 500 \mathrm{mb}-442 \mathrm{mb}$ y $200 \mathrm{mb}-150 \mathrm{mb}$.

En la fotografía del Meteosat se observan bandas nubosas que procedentes del Norte, circulan por el Cantábrico oriental, pero el centro de la 
fuerte borrasca se ha desplazado a un área comprendida entre el Este de Francia y el Norte de Italia, apreciándose fuerte nubosidad entre estos lugares. Por lo tanto, aunque la depresión va cediendo, todavia masas nubosas de cierta potencia afectan al Norte de Navarra.

La influencia de la borrasca y la llegada de masas nubosas del Norte dio lugar a la presencia de precipitaciones importantes en los Valles Cantábricos occidentales, en donde se midió una cantidad próxima o superior a los cuarenta milímetros (Artikutza, 64,2 mm.; Leitza, 53,3 mm.; Betelu, $46 \mathrm{~mm}$.; Alli, $37,3 \mathrm{~mm}$.). Sin duda, las masas de aire del Norte al chocar con los macizos de Cinco Villas y con la Sierra de Aralar, auténticas pantallas condensadoras de humedad, hicieron aumentar las precipitaciones. Los demás observatorios de los Valles Cantábricos y Pirenaicos Centrales fueron menos lluviosos (Santesteban, 26,7 mm.; Arizkun, $17 \mathrm{~mm}$.; Eugi, 15,3 mm.; Orbaitzeta, $16 \mathrm{~mm}$.). Por el contrario, Roncesvalles, situado al pie del macizo de Quinto Real también fue muy lluvioso $(39,3 \mathrm{~mm}$.).

El resto de comarcas de Navarra registraron escasas lluvias, salvo el Corredor del Arakil, junto a la Sierra de Urbasa (Alsasua, 20,2 mm.) y el Valle de Goñi, situado a bastante altitud y al pie de la Sierra de Andía (Goñi, 25,8 mm.). En Pamplona no se alcanzaron los diez milímetros (Pamplona-obs., 7,3 mm.).

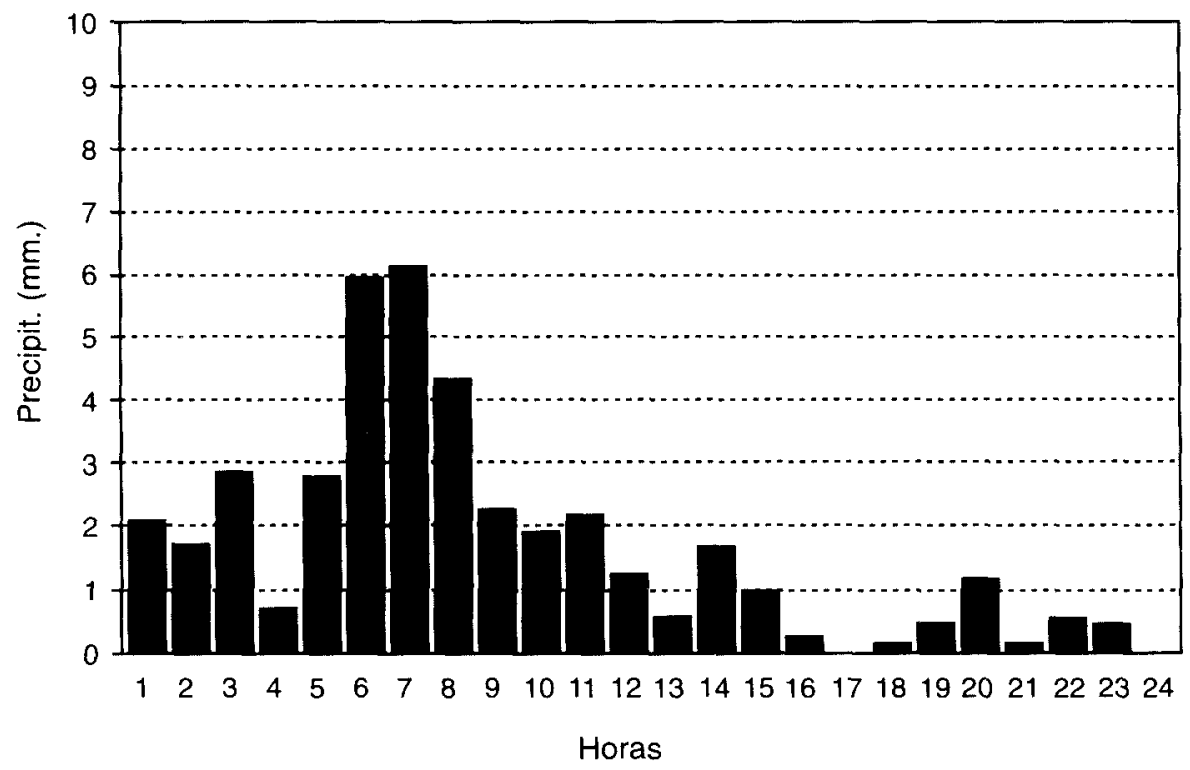

Gráfico 13. Roncesvalles. Precipitaciones dia 6-10-92. 


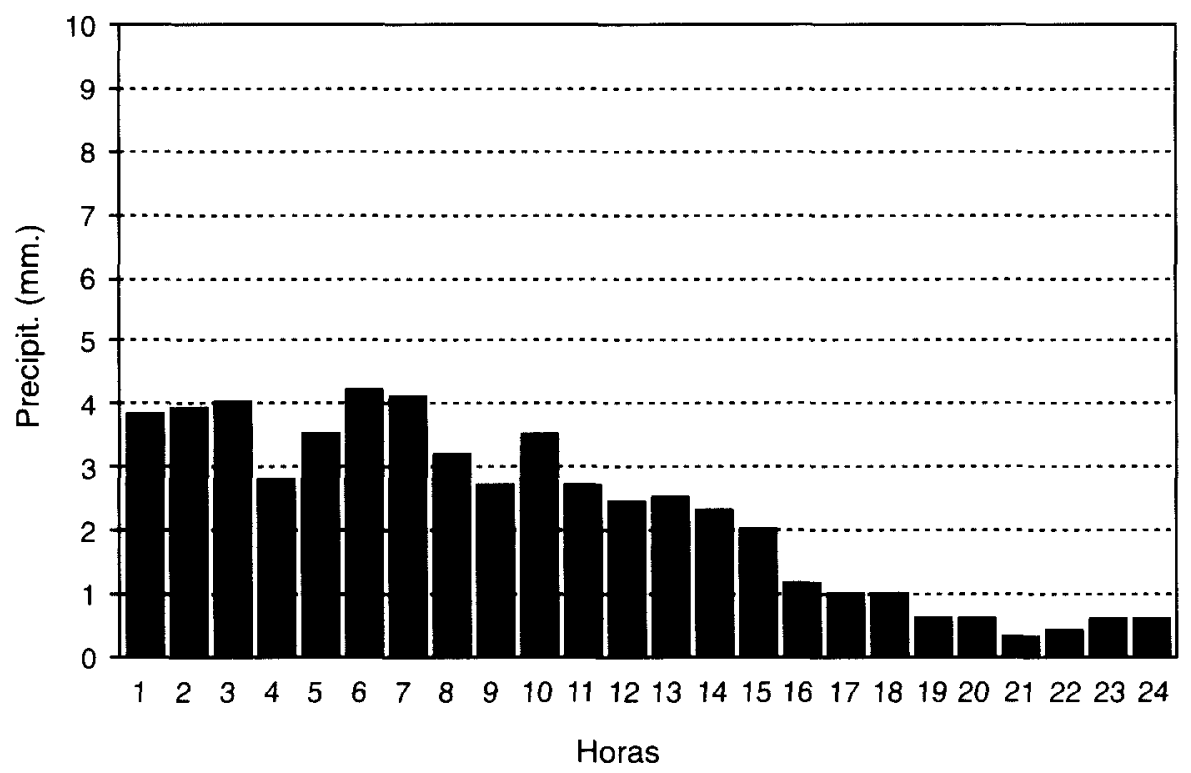

Gráfico 14. Irabia. Precipitaciones día 6-10-92.

La cantidad de agua recogida el día seis da una idea de la disminución de inestabilidad. En el observatorio de Roncesvalles (gráfico 13) se observa que estuvo lloviendo durante la primera mitad del día, siendo su mayor intensidad entre las cinco y las ocho de la mañana en que se recogieron $19 \mathrm{~mm}$. Por el contrario en la segunda mitad apenas se alcanzaron los $5 \mathrm{~mm}$., lo que demuestra la mejoría. Resultados en cierto modo parecidos se registraron en el observatorio del Irabia (gráfico 14). Las precipitaciones fueron más altas durante las diez primeras horas y posteriormente fueron disminuyendo progresivamente.

Durante el día seis descendió el caudal de los ríos navarros, si bien en algunas zonas se mantuvo todavía aito. Se registró una mejoría de las carreteras navarras coincidiendo con la disminución del temporal de lluvias, tan sólo la nacional 130, Pamplona-Tolosa, continuaba cortada en las cercanías de Irurtzun por el desbordamiento del río Larraun y se pedía precaución en la circulación ante la presencia de agua o barro en algunas calzadas. El río Arga a su paso por Pamplona redujo notablemente su caudal y se pudieron apreciar los daños importantes en la cimentación del puente de las Oblatas y las pérdidas registradas en las huertas de la Magdalena y de la Rochapea. Los ríos Arga, Aragón y Ebro tenían unos niveles muy superiores a los normales. 

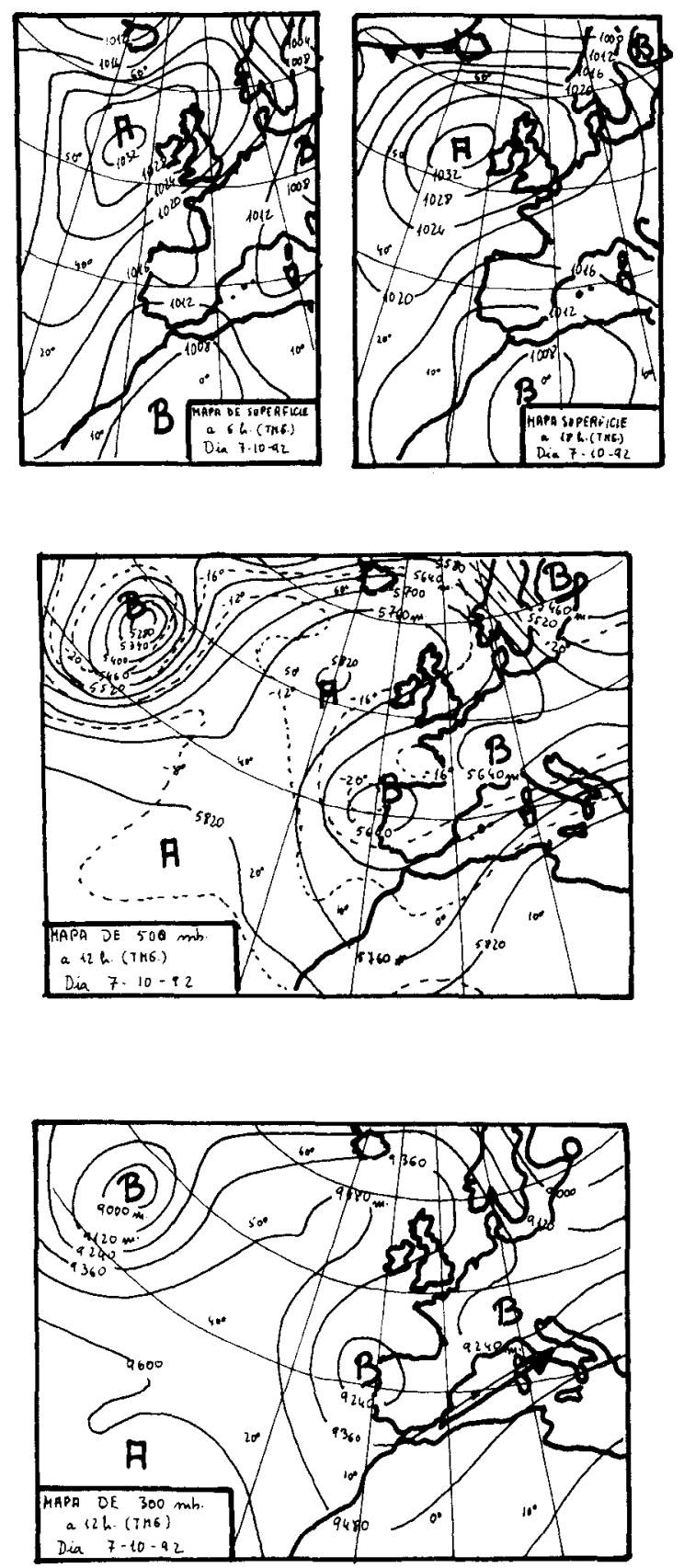

Mapa 7. 
El día siete supuso la finalización del temporal padecido en días anteriores. En el mapa de 500 milibares (mapa 7) se observa que la borrasca se va rellenando y la dorsal va imponiéndose sobre la vaguada. Navarra sigue dentro de la isoterma de dieciséis grados bajo cero, pero ahora se encuentra dentro de la isohipsa $5.700 \mathrm{~m}$., por lo que la presión experimenta un ascenso. Situación parecida se observa en la topografía de 300 milibares (mapa 7), en donde una rama de la corriente en chorro es del Suroeste en el Mediterráneo occidental.

En los mapas de superficie (mapa 7) la situación del Noreste del día anterior da paso a una otra del Este. Navarra se encuentra en la parte meridional de un anticiclón de bloqueo que se sitúa al Oeste de Irlanda. El gradiente de presión ha disminuido. La influencia del anticiclón del Atlántico es decisiva para la obtención de una mejoría total en Navarra y por lo tanto, una casi total ausencia de precipitaciones, con la única excepción de algunos puntos aislados de nuestra geografía que no llegan a alcanzar los $2 \mathrm{~mm}$. (Artikutza, 1,9 mm.; Valcarlos, 0,2 mm.; Orbaitzeta, $0,3 \mathrm{~mm}$., y Goñi, 0,3 mm.).

\section{LOS RESULTADOS DEL TEMPORAL DE LLUVIAS}

La cantidad de lluvia caída durante estos días demuestra el alcance de la potente borrasca. Para una mejor comprensión de los resultados se han sumado primeramente las precipitaciones totales obtenidas desde el dia uno hasta el siete de octubre. Las fuertes precipitaciones de octubre de 1992 que dieron lugar a las inundaciones en la Montaña navarra afectaron a tres zonas de nuestra Comunidad: los Valles Cantábricos, Valles Pirenaicos y zonas marginales pertenecientes estas últimas principalmente a los valles meridionales húmedos y al Corredor del Arakil.

Navarra Cantábrica muy bien situada en la parte occidental de la borrasca y lugar de paso de las masas nubosas que vienen del Noroeste y del Norte, fue la zona más lluviosa, pudiéndose distinguir dos subsectores. El primero de ellos, el más lluvioso, se situó en los Valles de UrumeaAñarbe y Leitzarán, en los que cayeron más de $350 \mathrm{~mm}$. en seis dias (Artikutza, $385 \mathrm{~mm}$.; Leitza, 388,3 mm.), cantidad muy alta y dificil de ser evacuada por los ríos. Sin duda, las masas de aire del Norte que circulaban al abrigo de la potente borrasca se vieron obligadas a un estancamiento en el macizo de Cinco Villas, lo que dio lugar a una mayor condensación y, en definitiva, a un considerable aumento de las lluvias. 
Precipitaciones elevadas pero inferiores se obtuvieron en el Valle de Araitz, Regata del Bidasoa y Valle del Baztán (gráfico 15), siempre por encima de los $240 \mathrm{~mm}$. en los seis días que duró el temporal (Betelu, 267,2 mm.; Santesteban, 242 mm.; Lekaroz, 243,9 mm.; Arizkun, 279,5 $\mathrm{mm}$.). Sin duda, la buena orientación de estos observatorios, situados a barlovento de la Sierra de Aralar, cadena divisoria Belate-Azpirotz y alineación septentrional del macizo de Quinto Real, explican la obtención de registros abultados (gráfico 15). Así pues, tanto el río Araxes como el Baztán-Bidasoa recibieron una enorme cantidad de agua que explica las inundaciones padecidas.

La segunda zona muy lluviosa se situó en los Valles Pirenaicos, bien orientados con respecto a la entrada de las masas nubosas inestables. La característica más importante de este área fue la variedad, pudiéndose distinguir al menos tres subsectores. El primero, uno de los más lluviosos, apareció en la cabecera de los Valles del Urrobi y del Irati, lugares que superaron los $300 \mathrm{~mm}$. en los seis días (Roncesvalles, $335,5 \mathrm{~mm}$.; Orbaitzeta, $345,3 \mathrm{~mm}$.). Sin duda, la alineación oriental del macizo de Quinto Real y el murallón de la Sierra de Abodi respectivamente, actuaron como auténticas barreras que dieron lugar al estancamiento de las masas de aire, fuertes

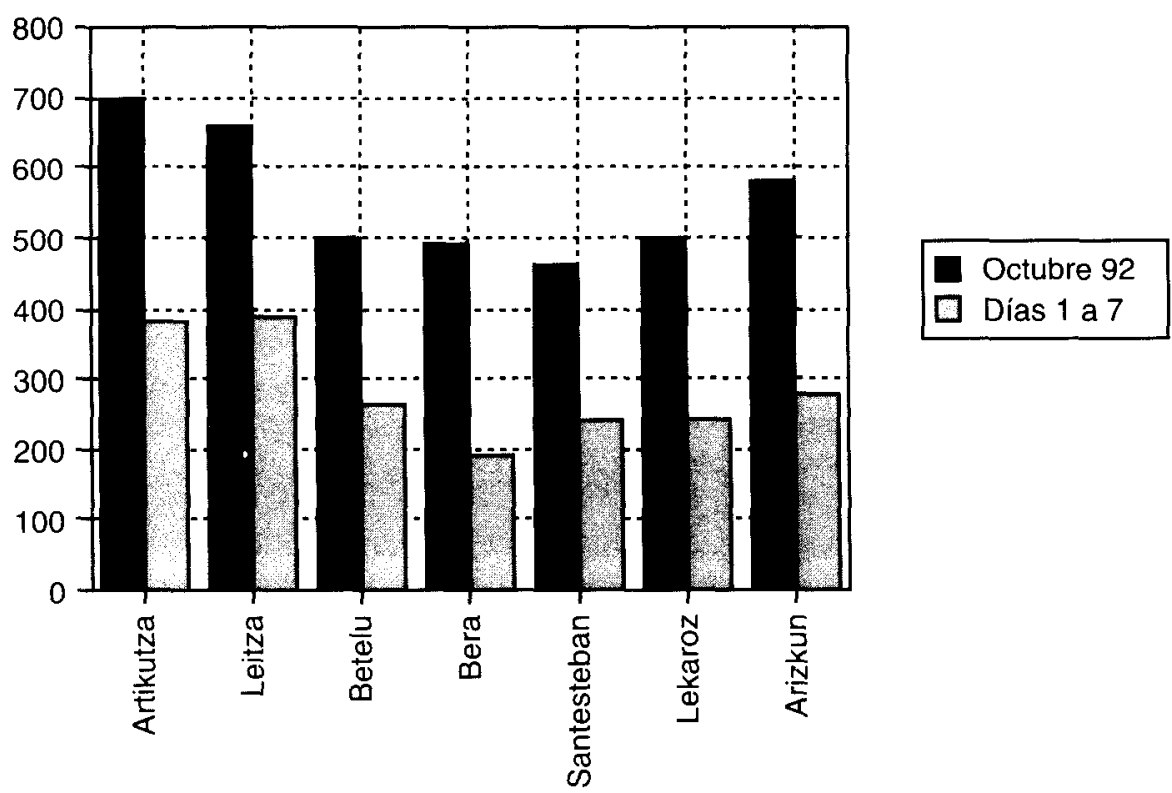

Gráfico 15. Valles Cantábricos. Precipitaciones (mm.). 


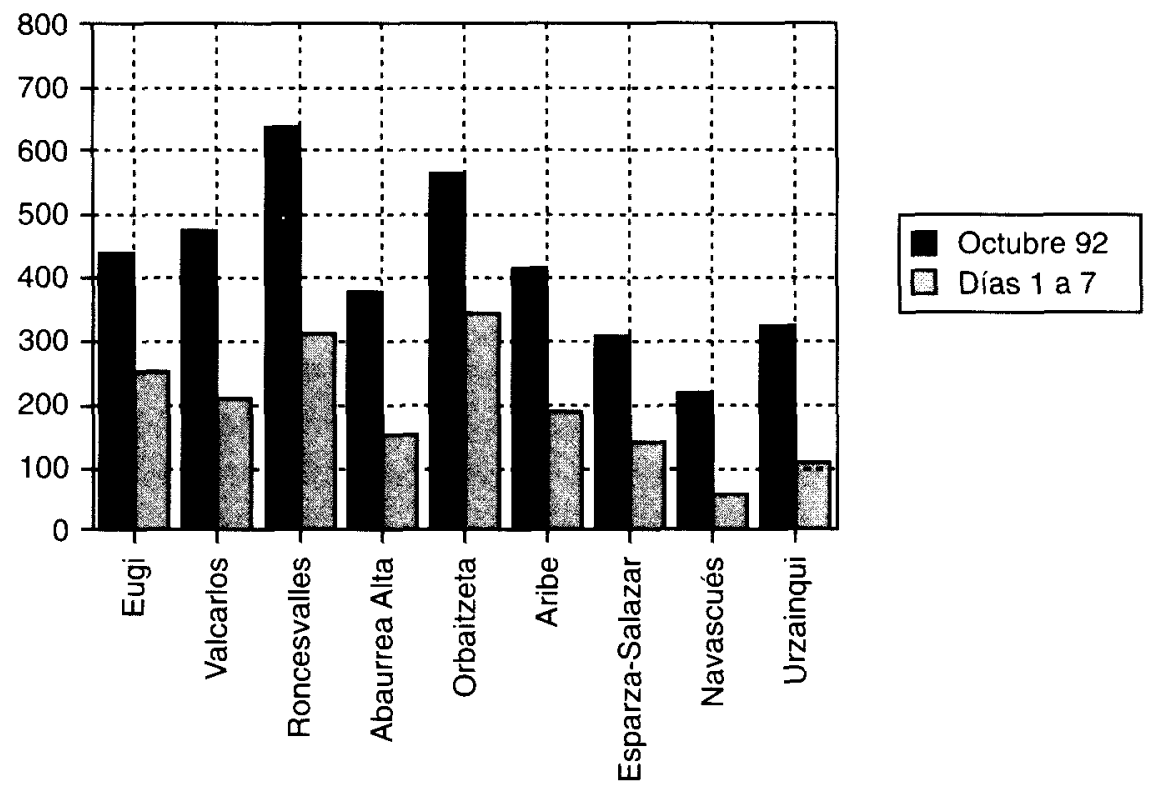

Gráfico 16. Valles Pirenaicos. Precipitaciones $(\mathrm{mm}$.).

ascensos y condensaciones, y, en definitiva, un aumento considerable en la cantidad de agua caída (gráfico 16). Por lo tanto, los ríos Irati y Urrobi difícilmente podían mantener en su cauce la gran cantidad de agua que descendía de las montañas circundantes por numerosos requeros.

Dentro de los Pirineos se puede distinguir un segundo subsector lluvioso representado por la cabecera del Valle del Arga y el enclave de Valcarlos (gráfico 16), que superaron los $200 \mathrm{~mm}$. de precipitación (Eugi, $248,8 \mathrm{~mm}$; Valcarlos, 209,5 mm.). La alta cantidad caída en el primero explica las crecidas aguas del río Arga a su paso por Pamplona, pese a la presencia en esta zona del pantano de Eugi. Conviene advertir, también, que los alrededores de Belate son muy lluviosos con situaciones del Norte. El resto de los observatorios de los Valles Pirenaicos recibieron, en todos los casos, más de $100 \mathrm{~mm}$. de precipitación y padecieron las riadas como consecuencia de las fuertes lluvias acaecidas aguas arriba (Abaurrea Alta, $148 \mathrm{~mm}$.; Aribe, 189,6 mm.; Esparza de Salazar, 141,1 mm.; Urzainqui, $113 \mathrm{~mm}$.). Se puede afirmar que en estos valles las precipitaciones disminuyeron hacia la parte oriental y meridional (gráfico 16).

La tercera zona lluviosa se registró en el Corredor del Arakil y Valles Larraun y Goñi, en alguno de cuyos observatorios se recogieron más de 
$300 \mathrm{~mm}$. (Alli, 306,7 mm.; Alsasua, 204,2 mm., y Goñi, 207,4 mm.). Sin duda, las Sierras de Aralar y el complejo montañoso Urbasa-Andía actuaron como fuertes pantallas de lluvias (gráfico 17).

Pero, las inundaciones son padecidas con mayor intensidad en las zonas llanas, en las que llovió menos que en las montañas. Las cabeceras de los valles se vieron afectadas por las lluvias, pero pronto pasó el peligro, debido a la rápida evacuación del agua hacia las zonas llanas. Cuando los pueblos de Orbaitzeta y Aribe estaban en situación de alarma todavía no había llegado la riada a Pamplona. Pero hay que tener en cuenta que el agua caída en la montaña acaba llegando al llano y, si las precipitaciones han sido elevadas, la riada anega los campos y, a veces, alcanza las partes bajas de la ciudad. Si la intensa lluvia está localizada en los Valles Cantábricos y Pirenaicos como en octubre de 1992, Navarra Media y la Ribera los ríos pueden llegar muy crecidos y salirse del cauce. Pero, si ocurre como en las Navidades de 1993, que llueve además en la Cuenca de Pamplona y en las Sierras de Aralar, Andía, Cantabria-Codés, Loquiz, etc., la inundación es grande en la Ribera.

Es importante comparar las precipitaciones caídas en la inundación de octubre de 1992 con las de diciembre de 1993, para sacar algunas conclu-

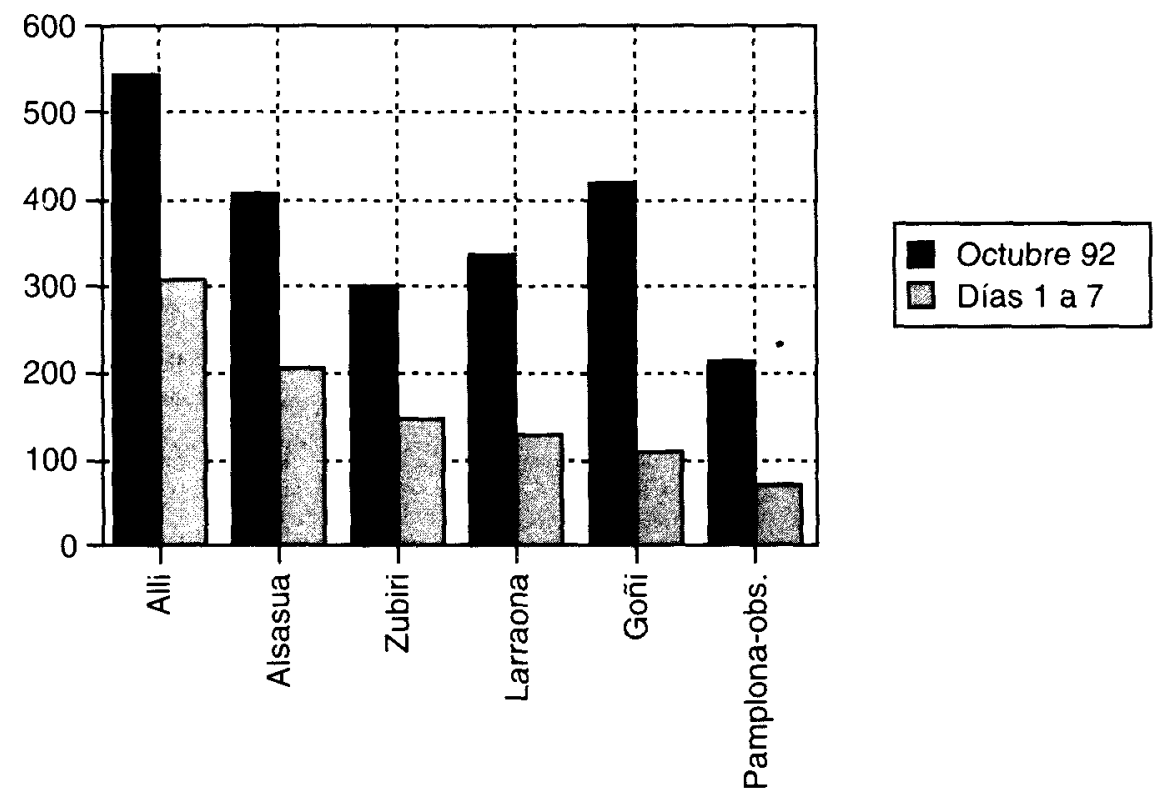

Gráfico 17. Otras zonas. Precipitaciones $(\mathrm{mm}$.). 
siones significativas. Las lluvias del 1 al 6 de octubre de 1992 fueron bastante parecidas a las del 23 al 28 de diciembre de 1993 en cuanto al total recogido. Llovió más en octubre de 1992 en los Valles Cantábricos (Artikutza, $385 \mathrm{~mm}$. en octubre de 1992, y 301,5 mm. en diciembre de 1993; Leitza, 388,3 mm., y $341 \mathrm{~mm}$., respectivamente). En la Regata del Bidasoa el balance fue bastante parecido (Santesteban, 242,2 mm. en octubre de 1992 y $245 \mathrm{~mm}$. en las de diciembre; Bera, 195,8 mm. y $206 \mathrm{~mm}$., respectivamente).

En los Valles Pirenaicos Centrales las lluvias del 1 al 6 de octubre de 1992 fueron superiores a las del 23 al 28 de diciembre de 1993, porque en esta zona estuvo localizado uno de los focos más lluviosos (Eugi, 248,8 mm., y $230 \mathrm{~mm}$., respectivamente; Roncesvalles, $335,5 \mathrm{~mm}$. y $230 \mathrm{~mm}$.). Por el contrario en los Valles Pirenaicos Orientales los resultados fueron parecidos (Esparza de Salazar, 141,1 mm. y 136,7 mm.; Urzainqui, 113 $\mathrm{mm}$. y $124 \mathrm{~mm}$.). Finalmente en el resto de las zonas llovió más durante los días 23 al 28 de diciembre (Alsasua, 204,2 mm. y 224,3 mm.; Larraona, $131 \mathrm{~mm}$. y 249,4 mm.; Goñi, 207,4 mm. y 310,6 mm.). Hay que destacar que en el observatorio de Goñi se registraron las más intensas lluvias de diciembre del 1993.

Una cuestión llama la atención después del estudio de los citados datos: las inundaciones del 23 al 28 de diciembre de 1993 fueron más aparatosas que las de los días 1 al 6 de octubre de 1992, siendo la cantidad caída bastante similar. Esto se explica porque en las primeras los focos lluviosos se dieron en los Valles Cantábricos y Pirenaicos principalmente, mientras que en las de diciembre las altas lluvias se extendieron por las Cuencas, el Corredor del Arakil y por algunos observatorios montañosos de Navarra Media, como es el caso de Larraona, Goñi, etc. Además la intensidad de lluvia fue mayor en los días 25 y 26 de diciembre, por lo que la cantidad de agua caída resultaba difícil de evacuar. Y finalmente en las de diciembre los suelos estaban empapados por las lluvias anteriores que habian caído, no sólo en diciembre sino en los meses de otoño.

El mes de octubre de 1992 ha pasado a la historia de la climatología como el mes más lluvioso de las series históricas desde el año 1941 en la mayor parte de los observatorios, debido a las fuertes lluvias que dieron lugar a la riada estudiada. La cantidad total de precipitación recogida en este mes fue muy elevada, sobre todo en los Valles Cantábricos y Pirenaicos y en las Cuencas. En Navarra Media y en la Ribera, si bien fueron superiores a la media, los resultados no se pueden considerar como abultados. 
En el observatorio de Artikutza, situado en los Valles Cantábricos (gráfico 18) octubre de 1992 ha sido el mes más lluvioso desde 1941, junto con el año 1974. Otros años lluviosos fueron 1980 (538 mm.) y 1982 $(507,1 \mathrm{~mm}$.). En esta serie se han contabilizado siete octubres lluviosos por encima de $400 \mathrm{~mm}$. y trece muy secos por debajo de los $100 \mathrm{~mm}$. En el observatorio de Santesteban, correspondiente al mismo sector (gráfico 19) el mes de octubre de 1992 ha sido el más lluvioso desde el año 1941 junto con el de 1974 y bastante diferencia con respecto a otros muy lluviosos: 1953 (301,4 mm.), 1966 (229,7 mm.) y 1974 (469,4 mm.). Se han contabilizado trece octubres lluviosos con más de $200 \mathrm{~mm}$. y once secos con menos de $50 \mathrm{~mm}$.

Lo mismo sucede en los Valles Pirenaicos. En el observatorio de Eugi (gráfico 20) octubre de 1992 fue el más lluvioso desde 1941, resultando muy lluviosos los de 1959 (413,3 mm.), 1974 (394 mm.), 1980 (408,1 mm.) y 1982 (316 mm.). En el observatorio de Abaurrea Alta (gráfico 21), perteneciente al mismo sector, octubre de 1992 fue el más lluvioso desde el año 1941, siendo otros octubres lluviosos los de 1960 (362,9 mm.), 1976 $(255,5 \mathrm{~mm}$.), 1980 (265,8 mm.), 1984 (263,5 mm.), 1987 (287,4 mm.), $1970(272 \mathrm{~mm})$.

En el Corredor del Arakil también se batieron marcas. Al estudiar los octubres desde el año 1941 en el observatorio de Alsasua (gráfico 22) se

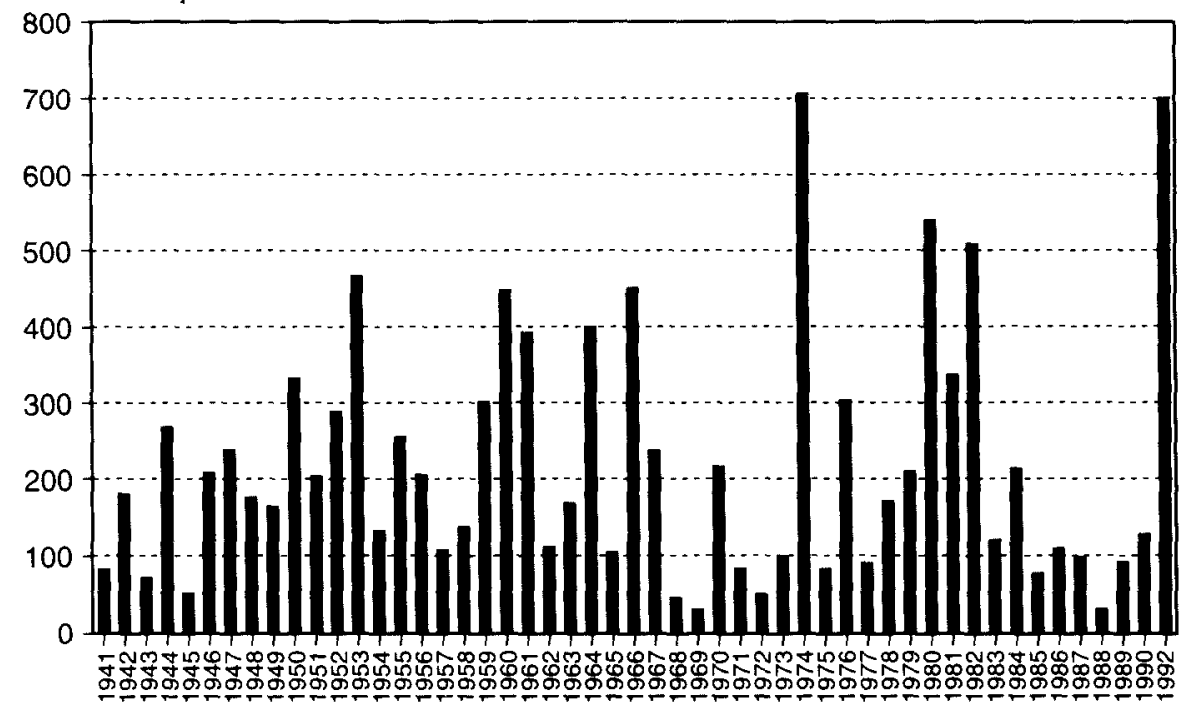

Gráfico 18. Artikutza. Precipitaciones de octubre 1941-90 ( $\mathrm{mm}$.). 


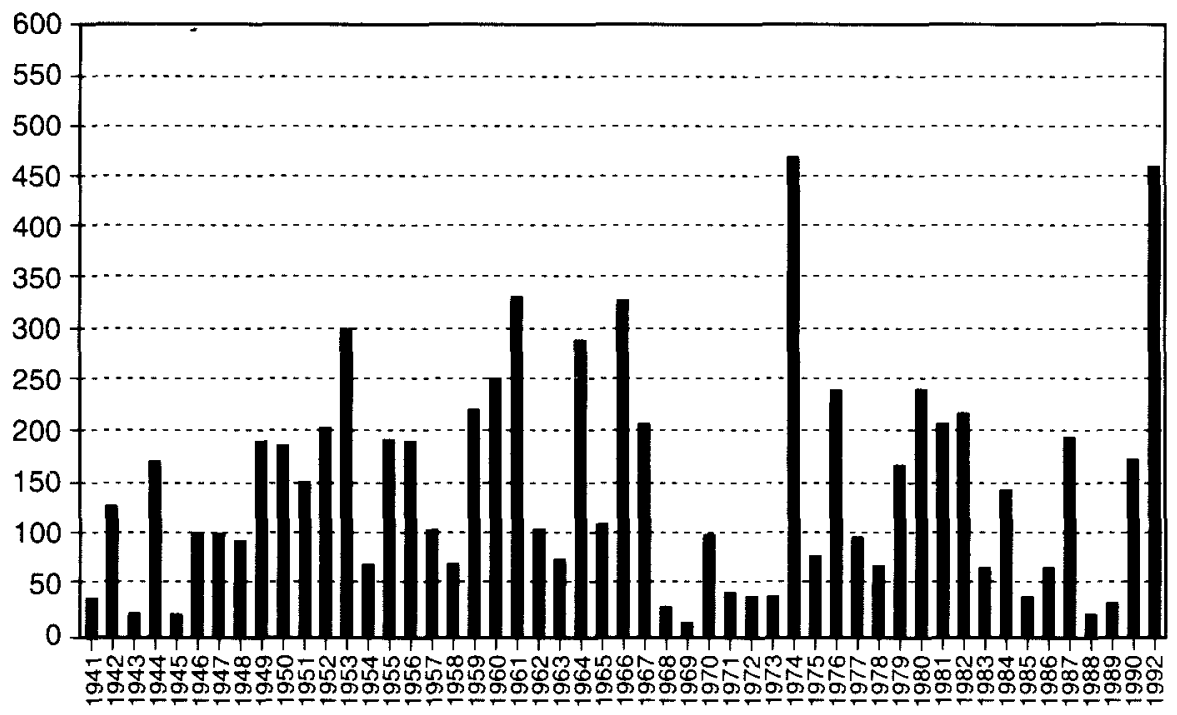

Gráfico 19. Santesteban. Precipitaciones de octubre 1941-90 (mm.).

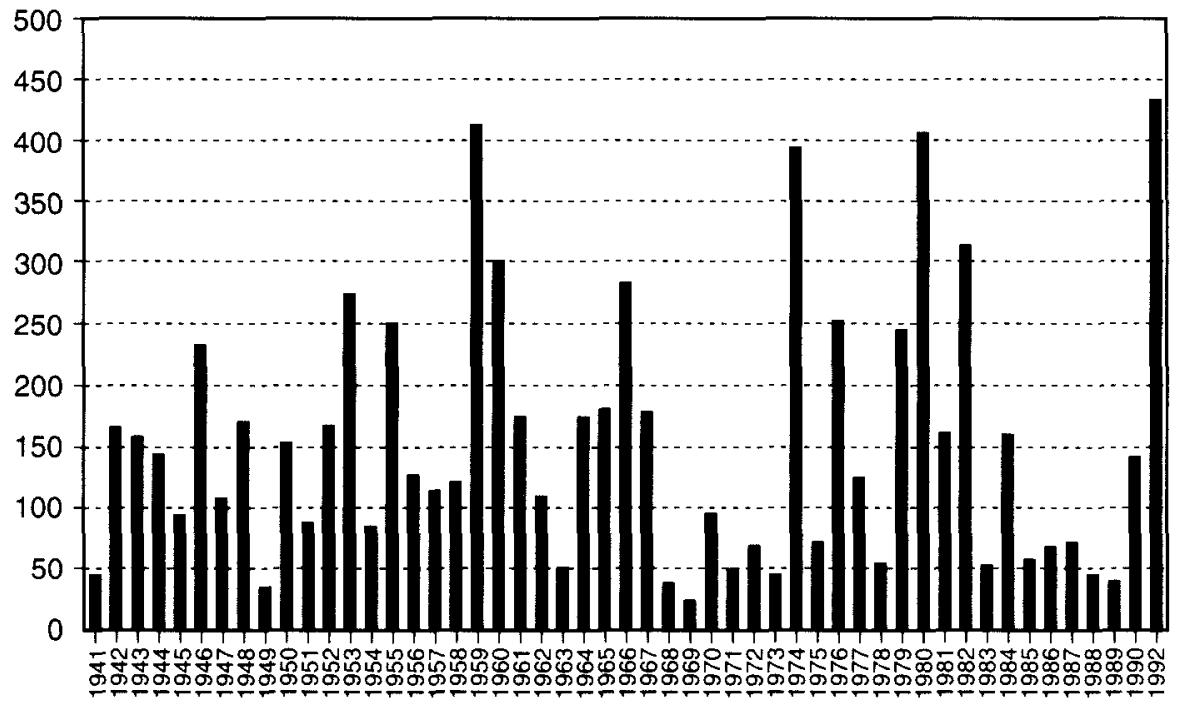

Gráfico 20. Eugi. Precipitaciones de octubre 1941-90 (mm.).

puede afirmar que el de 1992 fue el más lluvioso. Otros octubres lluviosos fueron los de 1953 (236,1 mm.), 1959 (261 mm.), 1960 (258 mm.), 1966 $(255,2 \mathrm{~mm}$.) y $1974(315,8 \mathrm{~mm}$.). 


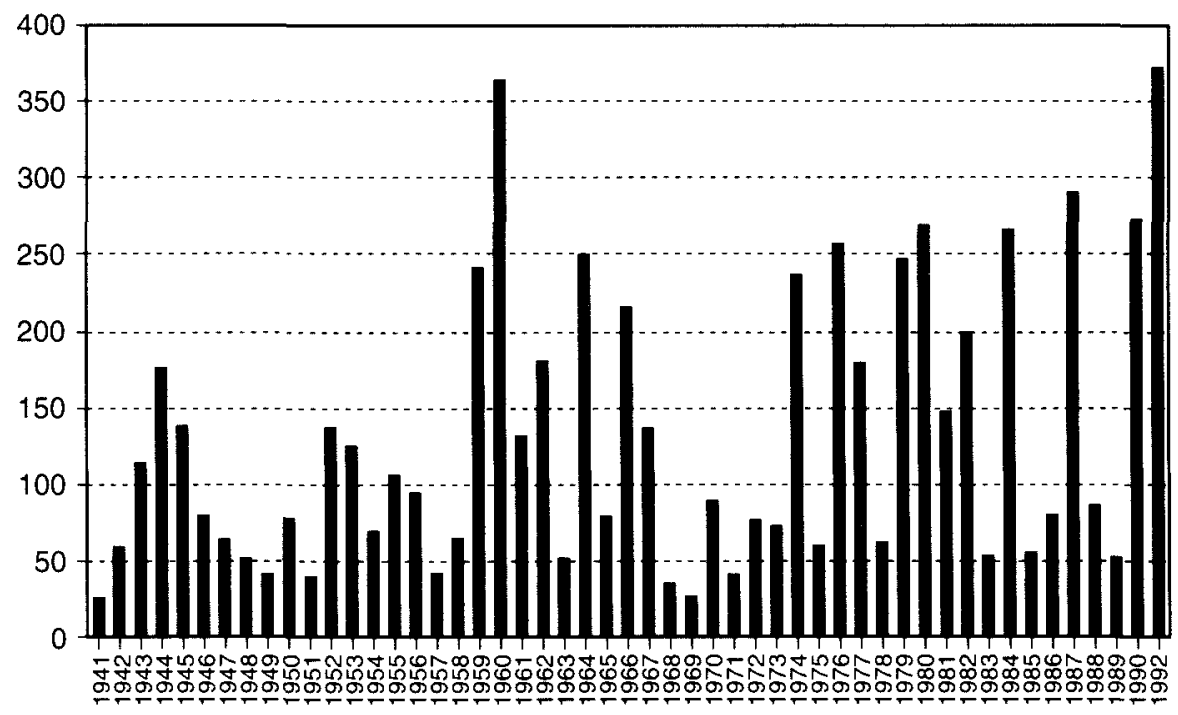

Gráfico 21. Abaurrea Alta. Precipitaciones de octubre 1941-90 (mm.).

\section{CONCLUSIONES}

El estudio de los parámetros alcanzados demuestran que las inundaciones de octubre de 1992 fueron muy pronunciadas en lugares concretos de los Valles Pirenaicos y Cantábricos, pero al no llover fuertemente en las zonas montañosas de las Cuencas y Navarra Media, los elevados caudales fueron localizados más bien en los Valles Cantábricos, Pirenaicos, Valles Meridionales húmedos, Corredor de la Barranca y Cuencas, siendo inferiores en Navarra Media y en la Ribera, comarcas estas últimas que han registrado crecidas más poderosas en numerosas ocasiones.

1. La dinámica atmosférica fue una de las causas de la inundación. Se han comparado las lluvias torrenciales de octubre de 1992 con las que dieron lugar a las últimas inundaciones acaecidas en Navarra, que sucedieron del 6 al 8 de diciembre de 1992 y del 25 al 28 de diciembre de 1993 y de su comparación se han sacado las siguientes conclusiones en cuanto a la dinámica atmosférica se refiere. En los tres casos se trata de una circulación del Oeste en altura de fuerte gradiente, que se ondula con anormal rapidez y adquiere una curvatura muy pronunciada. De este modo se pasa en un breve espacio de tiempo (uno o dos dias) de una situación del Oeste, con aire suave y escasas lluvias, a otra del Noroeste o del Norte muy inestable, porque entra en juego la orografía del Norte de Navarra. 


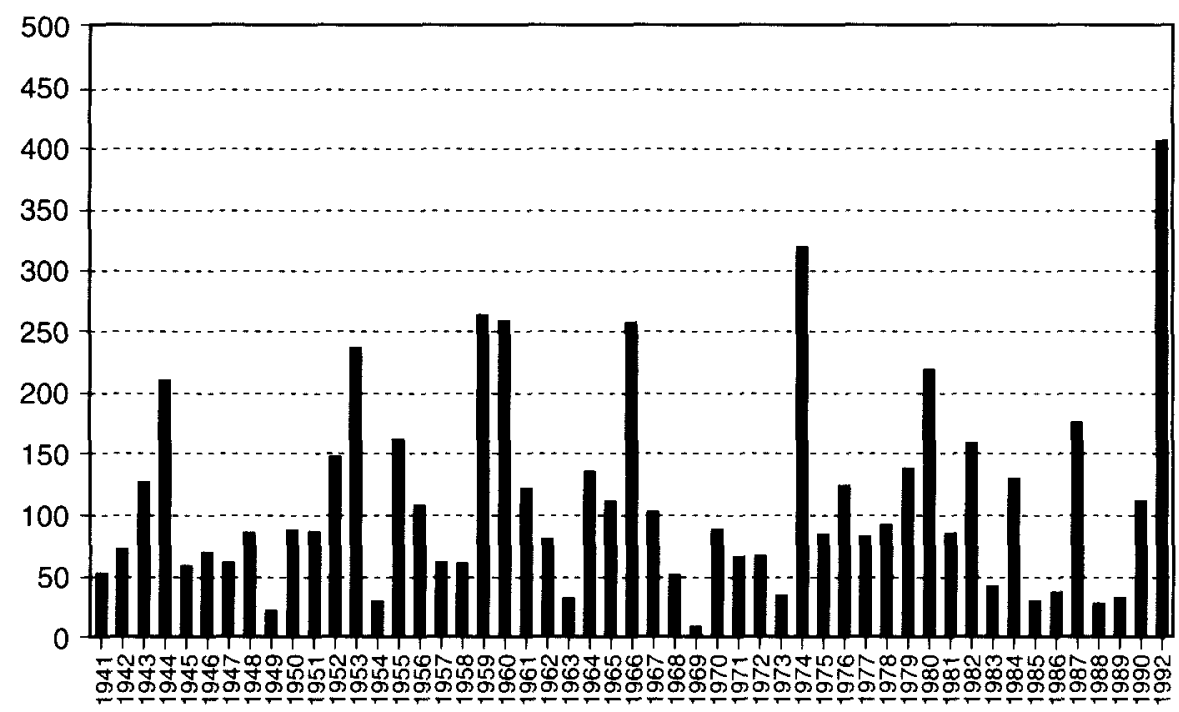

Gráfico 22. Alsasua. Precipitaciones de octubre 1941-90 ( $\mathrm{mm}$.).

En todos los casos afecta a Navarra una vaguada fría que se acaba convirtiendo en borrasca cerrada a niveles altos. Ésta se sitúa siempre en la parte oriental de Navarra, a la derecha, por lo que la inestabilidad y las masas de aire que penetran por esta trayectoria afectan de lleno. Así pues, Navarra se encuentra en el frente de ataque. Se trata de una circulación que se ondula de repente y se profundiza siguiendo el eje IslandiaIslas Británicas-Sudeste de Francia-Mediterráneo occidental. La corriente en chorro lleva mucha velocidad en todos los casos, y es del Noroeste y del Norte y atraviesa Navarra o sus cercanías, normalmente siguiendo la vía Cantábrico oriental-Mediterráneo.

En superficie aparecen potentes frentes fríos, asociados a situaciones de cuarto o de primer cuadrante (Noroeste y Norte) que en contacto con el relieve del Norte de Navarra producen brutales ascensiones e intensos chubascos. El gradiente de presión en la Península es muy elevado, oscila entre 1.000 y 1.004 milibares por una parte y 1.020 y $1.024 \mathrm{mb}$ por otra. En la topografía de 500 milibares entre 5.400 y $5.700 \mathrm{~m}$. En invierno la temperatura en esta altura oscila entre los 28 y 32 grados bajo cero, y en otoño entre los 20 y 28 grados bajo cero. Por lo tanto, presencia de aire muy frío en altura.

2. La situación y la orografía de nuestra Comunidad explican porqué se han producido en Navarra y no en otros lugares de España. En primer 
lugar porque las masas nubosas e inestables penetran por el Cantábrico oriental, especie de entrante abierto a las influencias del Atlántico, vía Navarra, por lo que nuestra Comunidad se encuentra en el frente de ataque. Navarra y a veces el País Vasco y Cantabria son las comunidades más lluviosas de la Península. En efecto, las masas de aire cargadas de humedad en su recorrido por el Atlántico nada más llegar a territorio navarro se ven obligadas a un estancamiento y ascenso para poder remontar las montañas del Norte de Navarra. Todo esto da lugar a violentas ascensiones que generan brutales condensaciones que provocan chubascos de gran intensidad. Por eso Navarra va a estar expuesta en algunas ocasiones al riesgo de inundación.

Varias son las montañas que realizan la función de pantallas pluviométricas. Primeramente el macizo de Cinco Villas situado en los Valles Cantábricos y responsable de las fuertes lluvias de los Valles del UrumeaAñarbe, Leitzarán, Araitz. En segundo lugar el macizo de Quinto Real que da lugar a los fuertes registros del Valle del Baztán, de la cabecera del Valle Esteríbar y del foco muy lluvioso de la cabecera del río Urrobi (Ilanada Espinal-Burquete-Roncesvalles). En tercer lugar los Pirineos orientales navarros, que por su altitud y su orientación zonal se constituyen en auténticos murallones que interceptan el paso de las masas de aire meridianas del Norte y del Noroeste. $Y$ dentro de los Pirineos, conviene subrayar el papel que desempeña la Sierra de Abodi, responsable, sin duda, de las inundaciones de octubre de 1992 en la cabecera del Irati, es decir en el pantano de Irabia. Evidentemente no será la primera vez, ni la última que este pantano registre fuertes crecidas, pues hay razones sobradas para ello.

La cadena divisoria Belate-Aspirotz puede resultar muy lluviosa cuando se instalan potentes áreas depresionarias y prueba de ello son las fuertes lluvias que se produjeron en esta zona y que dieron lugar a las inundaciones de las Navidades de 1993. En esta ocasión el río Ultzama que se nutre de las regatas, barrancos y fuentes de Belate, traía más agua que el río Arga y es el que verdaderamente aportaba fuerte caudal.

Si las precipitaciones se producen además con fuerte intensidad en el complejo montañoso Urbasa-Andía-Lóquiz la problemática es más seria y el riesgo de riada en Navarra Media y Ribera superior. Estas sierras orientadas zonalmente suponen un nuevo obstáculo para las masas de aire del Norte y del Noroeste y, en definitiva, un nuevo ascenso que se traduce en fuertes lluvias. Entonces los ríos Ubagua, Salado y Urederra, entre otros, se llenan rápidamente y aportan numeroso caudal al Arga y Ega respectivamente. 
3. Los lugares afectados por las inundaciones de octubre de 1992 fueron los Valles Cantábricos (Valles de Leitzarán, Araitz y Baztán), la cabecera de los Valles del Arga, Urrobi e Irati en los Valles Pirenaicos (principalmente la zona comprendida entre los pueblos de Orbaitzeta y Aribe), los Valles de Larraun y Arakil, y las Cuencas de Pamplona y de LumbierAóiz. En el gráfico 23 se observan los caudales medios registrados entre los días tres a diez de octubre de 1992 del río Irati en la estación de aforo de Aribe y del río Arga en las estaciones de aforo de Eugi, Huarte y Funes.

El río Irati en Aribe, que en días anteriores registraba un caudal ligeramente por encima de la media $\left(8 \mathrm{~m}^{3} / \mathrm{sg}\right.$. caudal del día 3 de octubre y $6,36 \mathrm{~m}^{3} / \mathrm{sg}$. caudal medio histórico de octubre) experimentó el día cuatro una crecida moderada $\left(29,72 \mathrm{~m}^{3} / \mathrm{sg}\right.$.) y muy fuerte entre los días cinco y seis $\left(293,6 \mathrm{~m}^{3} / \mathrm{sg}\right.$. y $248,7 \mathrm{~m}^{3} / \mathrm{sg}$., respectivamente). El día siete todavía el caudal era elevado $\left(98,01 \mathrm{~m}^{3} / \mathrm{sg}\right.$.) para ir descendiendo en los tres días posteriores $\left(24,72 \mathrm{~m}^{3} / \mathrm{sg}\right.$., $14,99 \mathrm{~m}^{3} / \mathrm{sg}$. y $17,72 \mathrm{~m}^{3} / \mathrm{sg}$.). Por lo tanto, la fuerte avenida tuvo lugar los días cinco y seis, jornadas en que el río se salió e inundó los terrenos colindantes.

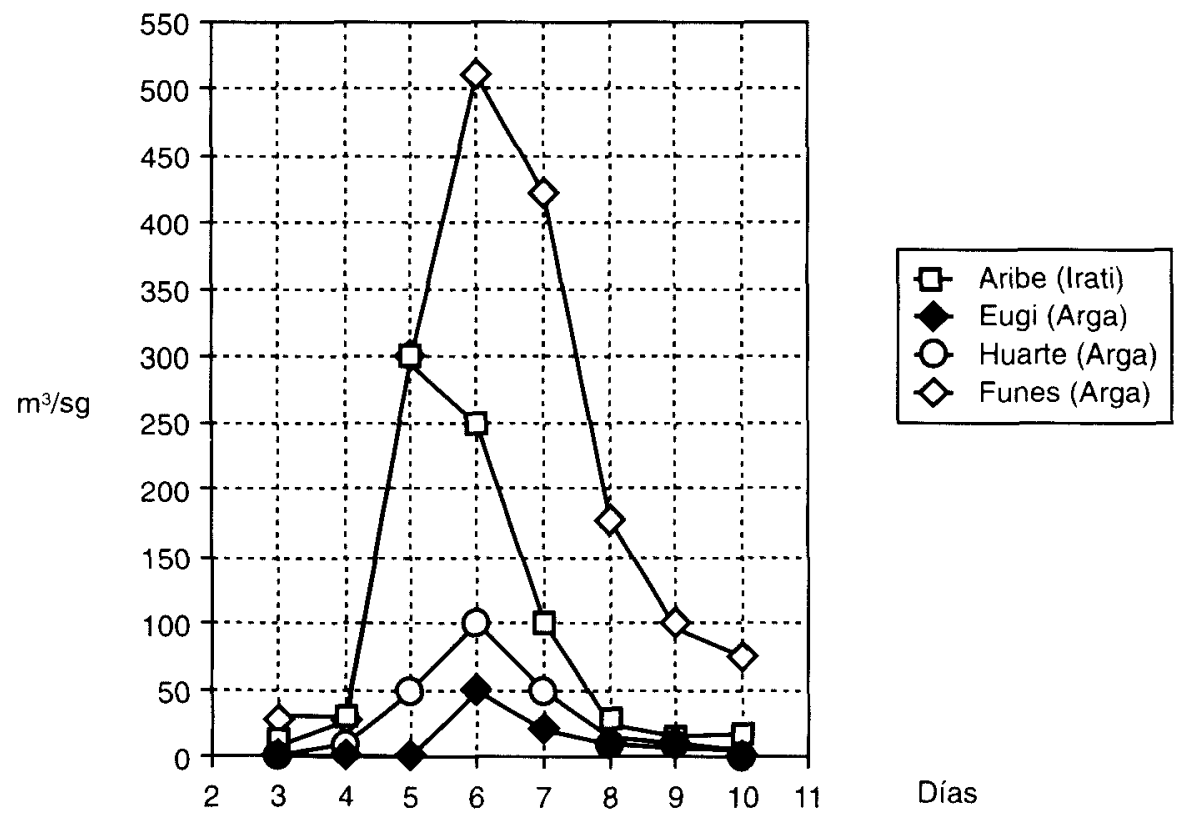

Gráfico 23. Caudales medios ( $\mathrm{m}^{3} / \mathrm{sg}$.) en octubre de 1992. 
La crecida de octubre de 1992 del río Irati en Aribe fue muy superior a la de las inundaciones de diciembre de 1992 que alcanzó el pico máximo el día ocho con $118,55 \mathrm{~m}^{3} / \mathrm{sg}$. y a las de diciembre de 1993 que registró $139 \mathrm{~m}^{3} / \mathrm{sg}$. el día 26 (gráfico 24). Así pues, en la cabecera del río Irati las precipitaciones y la riada fueron superiores en octubre de 1992 a las de diciembre de los años 1992 y 1993, y superó el máximo histórico que hasta entonces se había dado el 24 de diciembre de $1958\left(264 \mathrm{~m}^{3} / \mathrm{sg}\right.$.). También fue superior el pico que alcanzó este mismo río en la estación de aforo de Liédena $\left(372,6 \mathrm{~m}^{3} / \mathrm{sg}\right.$.) al obtenido en las inundaciones de diciembre de $1993\left(167,8 \mathrm{~m}^{3} / \mathrm{sg}\right.$. el día 26); sin embargo fueron inferiores al caudal máximo registrado en las inundaciones de diciembre de $1992\left(585,8 \mathrm{~m}^{3} / \mathrm{sg}\right.$. el dia 8 de diciembre). En ningún caso se llegó a la máxima histórica registrada el 30 de diciembre de $1960\left(680 \mathrm{~m}^{3} / \mathrm{sg}\right.$.).

El río Arga en Eugi registró el día 6 de octubre la crecida más elevada $\left(47,98 \mathrm{~m}^{3} / \mathrm{sg}\right.$. $)$ que fue superior a las de diciembre de 1992 y $1993(36,87$ $\mathrm{m}^{3} / \mathrm{sg}$. y $45,96 \mathrm{~m}^{3} / \mathrm{sg}$., respectivamente), y abonó la máxima histórica que hasta entonces se había medido el 20 de diciembre de $1969\left(32,5 \mathrm{~m}^{3} / \mathrm{sg}\right.$.). El río Arga en Huarte alcanzó el máximo caudal el día 6 de octubre $(98,9$ $\mathrm{m}^{3} / \mathrm{sg}$.), crecida inferior a las registradas en diciembre de 1992 y diciembre de $1993\left(111,7 \mathrm{~m}^{3} / \mathrm{sg}\right.$. y $119,1 \mathrm{~m}^{3} / \mathrm{sg}$., respectivamente). El máximo histó-

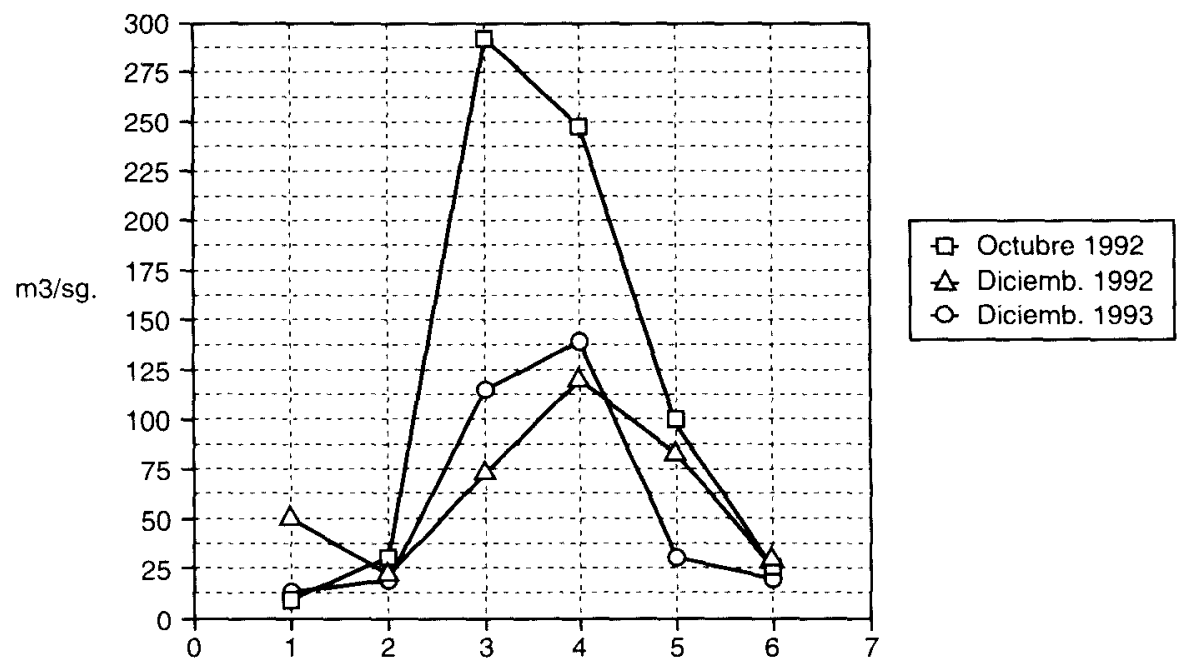

Dias 3 a 8 oct. de 1992; 5 a 10 de dic. de 1992; y 23 a 28 de dic. de 1993

Gráfico 24. Aribe (Irati). Caudal medio $\left(\mathrm{m}^{3} / \mathrm{sg}\right.$.) en las tres últimas inundaciones. 
rico de esta estación de aforo estaba el 4 de diciembre de $1969(77,9$ $\mathrm{m}^{3} / \mathrm{sg}$.). Este mismo río, en Funes (gráfico 23) registró las mayores caudales el día 6 de octubre de $1992\left(511,3 \mathrm{~m}^{3} / \mathrm{sg}\right.$.), cifra netamente inferior a las de diciembre de 1992 y $1993\left(710,5 \mathrm{~m}^{3} / \mathrm{sg}\right.$. y $684 \mathrm{~m}^{3} / \mathrm{sg}$.). En estos casos tampoco se superó la máxima histórica del 20 de diciembre de 1950 $\left(720 \mathrm{~m}^{3} / \mathrm{sg}\right.$.), si bien estos últimos datos corresponden a la estación de aforo de Peralta.

4. A la vista de los resultados obtenidos en las inundaciones de los últimos años se aprecian dentro de Navarra zonas de mayor riesgo de inundaciones cuando las precipitaciones son elevadas. En los Valles Cantábricos y dentro del sector Baztán-Bidasoa, Elizondo es un punto conflictivo, ya que recoge las aguas procedentes de cuencas muy lluviosas como las Sierras de Gorramendi y Autza (ríos Aranea, Maya y Beartzun). Narbarte y Oieregi están en zona de riesgo, pues se juntan las aguas procedentes de zonas de pluviometría elevada, como la de Belate y Legate, que es desaguada por las regatas de Marín y Zebería y las del Bértiz. Santesteban, también, porque es encrucijada de ríos que fluyen al Bidasoa (Ezkurra, Ameztia, Anizpe y Txaruta) y que suelen aportar mucha agua debido a las altas lluvias de las montañas circundantes.

En cuanto a los Valles Cantábricos occidentales, el río Urumea a su paso por Goizueta suele registrar alto caudal, pues se alimenta de las fuertes lluvias que caen en estas montañas. Los ríos Araxes y Leitzarán, dado su desnivel y su torrencialidad cuando las precipitaciones son elevadas, cosa no muy excepcional, experimentan fuertes crecidas.

Los ríos de los Valles Pirenaicos pueden ser los más expuestos a crecidas e inundaciones, porque se alimentan de una zona altamente lluviosa en la que caben registrarse altas precipitaciones, como viene ocurriendo en los últimos años. El curso del río Irati fue muy afectado por las inundaciones de octubre de 1992; en Orbaitzeta y Aribe se dan fuertes crecidas, pues se juntan, además, las aguas de Mendilaz y Txangoa y en el caso del segundo de Aztapar. Algunos lugares situados en la confluencia de rios y regatas son más propensos a inundarse: Aóiz (Irati y Urrobi), Aós (Irati y Erro), Lumbier (Irati y Salazar) y Sangüesa (Aragón e Irati).

La Cuenca de Pamplona es una zona de alto riesgo, pues es la primera llanura de cierta amplitud a la salida de los valles. El río Arga crece mucho cuando las precipitaciones son elevadas en el área de Belate y en los Pirineos Centrales. El área comprendida entre Huarte y Villava registra 
enseguida numerosas crecidas, pues el Arga recibe las aguas del Ultzama, río que en las inundaciones de diciembre de 1992 traía más agua que el Arga. Los lugares de Pamplona próximos al río (Magdalena, Rochapea, San Jorge) son anegados cuando las precipitaciones han sido elevadas en las cabeceras de los Valles Pirenaicos Centrales y en alto Belate; si además las precipitaciones han sido elevadas en los valles meridionales Húmedos y en la Cuenca de Pamplona, como ocurrió en diciembre de 1993, la riada alcanza mayores proporciones.

A partir de Pamplona el Arga aumenta su caudal en las inmediaciones de lbero a donde llega el importante aporte procedente de los ríos Arakil y Larraun. Navarra Media y la Ribera registran fuertes inundaciones cuando además ha caído bastante lluvia en el complejo montañoso Urbasa-AndiaLóquiz, cuyos ríos que van al Arga y Ega aportan fuerte caudal. Por otra parte el río Aragón, pese al embalse de Yesa, anega los pueblos y zonas ribereñas cuando las lluvias han sido altas en los Valles Pirenaicos o cuando ha habido fuerte deshielo.

5. Las características topográficas de los Valles Cantábricos y Pirenaicos, auténticos nidos de inundaciones, favorecen el aumento de riadas. Se trata en muchos casos de valles profundos, rodeados de fuertes pendientes y en cuyos fondos aparecen pocas llanuras y no muy amplias. Por lo tanto los rios tienen mucha pendiente y corto recorrido hasta que llegan al río principal y poco terreno llano para expansionarse. Así pues, en caso de desbordamiento, el nivel de las aguas sube rápido, como sucedió en Irabia, Aribe y Orbaitzeta.

La climatología de los últimos años favorece la presencia de crecidas en los ríos. El régimen de precipitaciones que se viene sucediendo en los últimos años es compatible sin duda con la presencia de altas lluvias. Últimamente se van reduciendo las precipitaciones de poca intensidad y duraderas y van dando paso a períodos secos que alternan con fuertes lluvias de chubascos. La presencia cada vez mayor de lluvias intensas hace que algunas de ellas se desarrollen con fuerte virulencia y terminen en riadas.

6. Una vez finalizadas las inundaciones se barajan algunas medidas a tomar para evitar en lo posible su repetición. Se habla, entre otras cosas, de dragar escolleras, de la eliminación de barreras que dificulten el transcurrir del agua, de limpiar los fondos de los cauces, de la mejora de los barrancos que más cauce han aportado en las riadas, de arreglar las márgenes rotas por el río y de reparar las zonas dañadas. 
Viendo los resultados obtenidos en las últimas inundaciones se cree necesario tener en cuenta algunas recomendaciones de cara a evitar o mitigar en lo posible el riesgo de inundación. En primer lugar conviene advertir que la eliminación del bosque autóctono y su sustitución por algunas especies de coníferas traídas de fuera, o por cultivos y pastos, o incluso por ausencia de vegetación, es contraproducente, pues se reduce mucho el papel protector que realiza la vegetación. Interesa que la concentración de agua, cuando ha habido fuertes lluvias, se retrase lo más posible, es decir que su velocidad sea menor.

En segundo lugar, habría que evitar los deslizamientos de tierras en las laderas. Para ello cuando se hacen carreteras, pistas o caminos, habrá que tomar las medidas correctoras oportunas con el objeto de mitigar los efectos negativos que estas obras producen. Lo mismo ocurre con los cultivos en pendiente. El terreno arcilloso, en pendiente y sin apenas vegetación, presente en algunos valles navarros, favorecen el deslizamiento de tierras.

También es importante tener en cuenta el impacto negativo de algunas construcciones en las cercanías de los ríos. Las casas situadas en su proximidad pueden reducir el cauce y hacer que el agua alcance una mayor altura y por lo tanto más velocidad. Las canalizaciones normalmente tienen efectos negativos, pues si bien sirven para reducir la inundación en un lugar concreto, al aumentar la velocidad de evacuación ya que disminuye la resistencia, se corre el riesgo de pasar el problema al vecino de más abajo. Por otra parte la tala cada vez más frecuente de árboles y arbustos en las riberas de los ríos hace que el agua se acelere más y produzca efectos mayores.

Cuando se trata de planificar nuevas construcciones o reconstruir to que fue anegado conviene que se lleve a cabo una planificación concienzuda. Sería necesario abordar el problema no localmente de una ciudad o un pueblo concreto, sino de un modo global relativo a toda la cuenca. Conviene destacar que en situación de riada las llanuras son como desembocaduras y las edificaciones que se sitúan junto a ellas, si adoptan medidas de contención, están trasladando el problema a otras zonas más bajas, en donde los efectos pueden ser más catastróficos. Por lo tanto, en el área de terrazas próxima al río habrá que tener en cuenta cómo se lleva a cabo la ocupación del territorio.

Los lugares en donde confluyen los ríos son peligrosos cuando las precipitaciones son altas, sobre todo si los caudales máximos coinciden todos 
a la vez. Todo lo que evite las retenciones y favorezca la rápida evacuación será positivo para estos sitios. Dado que nuestro clima y nuestra topografía favorecen la presencia de altas precipitaciones y que éstas no serán las últimas se impone estar preparados para afrontarlas.

Las medidas más oportunas a tomar para reducir el riesgo de inundacióri a nuestro parecer serían las siguientes: la planificación coordinada y no individual en los diferentes puntos de la cuenca; la realización de estudios sobre el comportamiento de aguas en las laderas, viendo las zonas más críticas; la repoblación de masas forestales con especies que se adapten a la comarca concreta en los valles y en las riberas; la retirada de asentamientos humanos de las zonas más peligrosas; el aprovechamiento agropecuario con especies que se adapten a las características del terreno, y la construcción de las vías de comunicación sin coincidir con los puntos con más riesgo de crecidas de los ríos. Pero, sobre todo, habrá que tener en cuenta que no se puede buscar una solución para un lugar aislado, sino que habría que planificar actuaciones de un modo global que conjuguen los intereses medioambientales con los de la población que se ve dañada.

\section{BIBLIOGRAFIA}

ALbentosa, L. M. (1983): “Precipitaciones excepcionales durante los días 6 a 8 de noviembre de 1982 en Cataluña". Estudios Geográficos, mayo, pp. 229-275, Madrid.

Bautista Martin, J. (1989): "Las avenidas en la cuenca del Segura y los planes de defensa", en avenidas fluviales e inundaciones en la cuenca del Mediterráneo, Alicante, Caja de Ahorros del Mediterráneo e Instituto Universitario de Geografía de la Universidad de Alicante.

Bel. iRán, F., y PEJenaute, J. (1995): "Las inundaciones en Navarra", en II Reunión del Grupo de Climatología, Jaca, Instituto Pirenaico de Ecología y C.S.I.C., pp. 129-140.

Caja de Ahorros de Navarra (1991): El agua en Navarra, Pamplona, Caja de Ahorros de Navarra.

Calvo Garcia-Tornel, F. (1989): "Grandes avenidas e inundaciones históricas", en avenidas fluviales e inundaciones en la cuenca del Mediterráneo. Alicante, Caja de Ahorros del Mediterráneo e Instituto Universitario de Geografía de la Universidad de Alicante.

Capel Molina, J. (1983): El clima de la España Cantábrica. Las inundaciones de agosto de 1983 en el País Vasco, Cantabria y Navarra Atlántica, Almería, La Crónica.

- (1987): “Inundaciones y avenidas de los ríos del Sureste Español», Papeles de Geografía, n. ${ }^{\circ} 13$, pp. 75-86, Universidad de Murcia.

- (1990): “Ciclogénesis violenta en el Mediterráneo", Papeles de Geografía, n. ${ }^{\circ}$ 16, pp. 9-33, Universidad de Murcia.

Comunidad autónoma del País Vasco (1989): Euskadi 83, lluvias torrenciales, Vitoria, Departamento de Urbanismo, Vivienda y Medio Ambiente del Gobierno Vasco.

Creus Movau, J. (1986): Climatología (Gran Atlas Geográfico e Histórico de Navarra), Pamplona, Caja de Ahorros de Navarra, pp. 83-90.

Creus, J., y Puigdefabregas, J. (1978): “Influencia del relieve en la distribución de las precipitaciones máximas. Un ejemplo Pirenaico", Cuadernos de Investigación, 4, pp. 11-23, Colegio Universitario de Logroño. 
Font Tullot, I. (1988): Historia del clima de España, cambios climáticos y sus causas, Madrid, I.N.M.

Garcia, J.; Puigdefabregas, J., y Martin-Ranz, M. C. (1983): “Diferencias espaciales en la respuesta hidrológica a las precipitaciones torrenciales de noviembre de 1982 en el Pirineo Central', Estudios Geográficos, 171, pp. 291-311, Madrid.

GARCIA GONZALEZ, L. (1991): "Las inundaciones en Extremadura: Problemática y futuro", en XII Congreso de Geografía, Valencia, pp. 159-165.

GHL OLCINA, A. (1983): «Inundaciones de octubre de 1982 en el campo de Alicante», Estudios Geográficos, 171, pp. 121-143, Madrid.

- 1991: "Avenidas fluviales e inundaciones", en Atlas temático de la Comunidad Valenciana n. ${ }^{\circ} 8$, Alicante, Diario Información, Editorial Prensa Alicantina.

GIL OlCinA, A., y MORAles GIL, A. (1988): «Prevención de riadas en la provincia de Alicante» (Proyecto de investigación), Universidad de Alicante.

- 1992: «Riesgo e incidencia de riadas en instalaciones industriales e instalaciones básicas para el suministro de energía eléctrica en la provincia de Alicante (Proyecto de investigación), Universidad de Alicante.

LÓPEZ BERmúdez, F. (1983): “Descripción y experiencias de la avenida e inundación de octubre de 1982 en la cuenca del Segura", Madrid, Estudios Geográficos, núms. 170-171.

LÓPEZ GOMEZ, A. (1989): "Aguaceros extraordinarios e inundaciones en la cuenca del Mediterráneo española (1957-1982)", en Avenidas fluviales e inundaciones en la cuenca del Mediterráneo, Alicante, Caja de Ahorros del Mediterráneo e Instituto Universitario de Geografía de la Universidad de Alicante.

Llasat BotinA, M. C. (1991): Gota fría, Barcelona, Boixareu, 165 páginas.

MARTIN VIDE, J. (1979): Características climatológicas de la precipitación en la franja costera Mediterránea de la Península Ibérica, Barcelona, Generalitat de Catalunya.

- 1985: Fluges e inundacions a la Mediterrània. Barcelona. Ketres.

Mateu Bellés, J. (1988): "Crecidas e inundaciones en el Pais Valenciano", en Guía de la Naturaleza de la Comunidad Valenciana, Valencia, Generalitat Valenciana, pp. 595-654.

- 1990: “Avenidas y riesgo de inundación en los sistemas fluviales mediterráneos de la Península Ibérica», Boletín de la A.G.E., n. ${ }^{\circ} 10$, pp. 45-86, Madrid.

Olcina Cantos, J. (1992): “Fenómenos de retrogresión estivales en el ámbito mediterráneo: desarrollos ciclogenéticos, sistemas convectivos de mesoscala y lluvias intensas. El episodio de 27 de septiembre a 7 de octubre de 1986", Alicante, Investigaciones Geográficas, enerojunio, pp. 79-102.

- (1994): Tormentas y granizadas en las tierras alicantinas, Universidad de Alicante, Instituto Universitario de Geografía, 317 páginas.

- (1994): Riesgos climáticos en la Península Ibérica, Madrid, Penthalon, 440 páginas.

- (1995): “Factor climático y la ordenación del territorio: los riesgos climáticos", Ponencia presentada a la II reunión del grupo de climatología, Jaca, Instituto Pirenaico de Ecología y C.S.I.C., septiembre, pp. 15-69.

Olcina Cantos, J., y CAPEL Molina, J. J. (1993): “Ondas cortas atmosféricas estivales y fenómenos tormentosos con granizo en el Sureste peninsular ibérica", Papeles de Geografía, 19, pp. 1-35, Murcia.

Olcina Cantos, J., y Quereda SalA, J. (1994): “Liuvias de barro en la vertiente mediterránea de la Península Ibérica", Alicante, Investigaciones Geográficas, enero-junio, pp. 7-22.

PEJENAUTE GoNII, J. (1989): "Los dias de precipitación elevada en Navarra y las situaciones atmosféricas que los originan", Notas y Estudios de Ciencias Sociales, 2, pp. 17-60, Centro Asociado de la UNED de Navarra, Pamplona.

- (1990): “Las situaciones atmosféricas lluviosas en Navarra", Espacio, Tiempo y Forma, serie VI, Geografía, pp. 113-150, Universidad a Distancia, Madrid.

- (1990): “Estudio de las precipitaciones torrenciales de agosto de 1983 en Navarra", Lurralde, 14, pp. 117-142, INGEBA, San Sebastián.

QUEREDA, J. (1983): “Los excepcionales temporales de octubre y su relación con las temperaturas del mar", Cuadernos Geográficos de Valencia, pp. 1-13, Valencia. 
- (1984): «Perturbations atmospheriques et temperature marine en Méditerranée Occidentale", Mediterranée, 3, pp. 11-16, Aix.

- (1989): La ciclogénesis y las gotas frías en el Mediterráneo Occidental, Castellón, Colegio Universitario y Diputación.

Rivera, A. (1990): “Las situaciones de lluvias torrenciales en el área mediterránea española y el plan PREVIMET" en la meteorologia en el mundo iberoamericano", I.N.M., n. ${ }^{\circ} 2$, octubrediciembre, Madrid.

URIARTE, A. (1982): “Duración de las precipitaciones e intensidades en tiempos cortos en San Sebastián", Lurralde, pp. 21-34, San Sebastián, INGEBA.

- (1983): El régimen de precipitaciones en la costa $N W$ y $N$ de la Península lbérica, San Sebastián, Caja de Ahorros de Guipúzcoa. 